\title{
Differential regulation of mitochondrial complex I and oxidative stress based on metastatic potential of colorectal cancer cells
}

\author{
NEERAJ KUMAR RAI ${ }^{1}$, SHASHANK MATHUR ${ }^{2}$, SURAJ KUMAR SINGH $^{3}$, MEENAKSHI TIWARI $^{3}$, \\ VIJAY KUMAR SINGH ${ }^{4}$, RIZWANUL HAQUE ${ }^{1}$, SWASTI TIWARI $^{2}$ and LOKENDRA KUMAR SHARMA ${ }^{2}$ \\ ${ }^{1}$ Department of Biotechnology, Central University of South Bihar, Gaya, Bihar 824236; \\ ${ }^{2}$ Department of Molecular Medicine and Biotechnology, Sanjay Gandhi Post Graduate Institute of Medical Sciences, \\ Lucknow, Uttar Pradesh 226014; ${ }^{3}$ Department of Pathology/Lab Medicine, All India Institute of Medical Sciences-Patna, \\ Patna, Bihar 801507; ${ }^{4}$ Department of Bioinformatics, Central University of South Bihar, Gaya, Bihar 824236, India
}

Received May 4, 2020; Accepted September 3, 2020

DOI: 10.3892/ol.2020.12176

\begin{abstract}
Mitochondria serve a vital role in cellular homeostasis as they regulate cell proliferation and death pathways, which are attributed to mitochondrial bioenergetics, free radicals and metabolism. Alterations in mitochondrial functions have been reported in various diseases, including cancer. Colorectal cancer (CRC) is one of the most common metastatic cancer types with high mortality rates. Although mitochondrial oxidative stress has been associated with CRC, its specific mechanism and contribution to metastatic progression remain poorly understood. Therefore, the aims of the present study were to investigate the role of mitochondria in CRC cells with low and high metastatic potential and to evaluate the contribution of mitochondrial respiratory chain (RC) complexes in oncogenic signaling pathways. The present results demonstrated that cell lines with low metastatic potential were resistant to mitochondrial complex I (C-I)-mediated oxidative stress, and had C-I inhibition with impaired mitochondrial functions. These adaptations enabled cells to cope with higher oxidative stress. Conversely, cells with high metastatic potential demonstrated functional C-I with improved mitochondrial function due to coordinated upregulation of mitochondrial biogenesis and metabolic reprogramming. Pharmacological inhibition of C-I in high metastatic cells resulted in increased sensitivity to cell death and decreased metastatic signaling. The present findings identified the differential regulation of mitochondrial functions in CRC cells, based on CRC metastatic potential. Specifically, it was suggested that a functional $\mathrm{C}-\mathrm{I}$ is required for high metastatic features of cancer cells, and
\end{abstract}

Correspondence to: Dr Lokendra Kumar Sharma, Department of Molecular Medicine and Biotechnology, Sanjay Gandhi Post Graduate Institute of Medical Sciences, 4th Floor, PMSSY Building, Raebareli Road, Lucknow, Uttar Pradesh 226014, India

E-mail: rajlokendra@yahoo.co.in

Key words: mitochondria, mitochondrial complex I, oxidative stress, colorectal cancer, metastasis, apoptosis the role of C-I could be further examined as a potential target in the development of novel therapies for diagnosing high metastatic cancer types.

\section{Introduction}

Mitochondria are the bioenergetic and metabolic hubs of the cell, and are harbor sites of free radical generation (1). Free radicals can regulate cellular signaling pathways and contribute to cellular proliferation and death mechanisms (2). Changes in mitochondria, such as respiration impairments, oxidative stress and metabolic alterations, affect these signaling pathways and are associated with various diseases, including cancer (3). In cancer, mitochondrial contribution is variable and dependent on the type of cancer, genetic factors, tissue origin and other unknown factors (4). In mitochondria, respiratory chain (RC) complexes are large multi-subunit inner membrane structures that facilitate electron transfer, ATP production via oxidative phosphorylation (OXPHOS) and reactive oxygen species (ROS) generation. Since ROS levels act as signaling molecules to activate cellular pathways, excessive ROS levels can cause oxidative damage and contribute to oncogenic signaling for cancer development (5). Previous studies have reported that oxidative stress is a mitigating factor in metastasis, and the threshold of oxidative stress is crucial in enhancing or decreasing metastatic potential $(6,7)$. From the metabolic perspective, while cancer cells are highly glycolytic (Warburg effect), it is now evident that reprogramming of metabolic pathways serves a critical role in proliferation of cancer cells (8). However, the contribution and role of RC in metabolic reprogramming in cancer progression are yet to be fully elucidated.

Among the five types of mitochondrial RC complexes, mitochondrial complex I (C-I; NADH: Ubiquinone oxidoreductase) is the largest and most prolific ROS producing site, and has been implicated in cancer progression (9-14). C-I alterations are involved in mitochondrial dysfunction in different cancer types, including lung, liver, prostrate breast and colon cancer (14). While the specific role of C-I in promoting or suppressing tumors remains unknown, it largely depends on cancer types and the experimental system (15). Since metastatic processes involve cell 
migration, invasion and proliferation at distal sites, C-I-mediated changes could serve an important role in regulating metastatic signaling (16). Hence, it is imperative to understand how different $\mathrm{RC}$ complexes regulate proliferative pathways and contribute to these pathways at different stages of neoplastic transformations. Such studies are clinically relevant in targeting specific $\mathrm{RC}$ complexes, as well as combining therapeutic approaches to specific metastatic conditions and tumor types.

Colorectal cancer (CRC) is the fourth most common type of cancer with high incidence $(6.1 \%)$ and mortality $(5.8 \%)$ rates across all cancers worldwide according to global cancer statistics 2018 (17). Although mitochondrial alterations have been associated with CRC metastasis, the functionality of different $\mathrm{RC}$ complexes, contribution of oxidative stress and the role of metastatic signaling in CRC remain unknown. Therefore, it is clinically relevant to identify therapeutic targets.

The current study aimed to identify specific changes in $\mathrm{RC}$ complexes, as well as their contribution to mitochondrial dysfunctions and metabolism in metastatic CRC cells. Using CRC cells with low and high metastatic potentials, the present study aimed to investigate the effect of RC inhibition on cell survival, mitochondrial functions and contribution to metastatic signaling pathways.

\section{Materials and methods}

Cell culture. Established CRC cell lines (low metastatic, HT-29 and HCT-15; high metastatic, HCT-116 and COLO-205) were used in the current study. These authenticated cell lines were purchased from the national repository at National Centre for Cell Sciences Pune, and early passage cultures were used for performing all the experiments. Cell culture reagents, including growth media, FBS and antibiotics were purchased from HiMedia Laboratories LLC. HT-29, HCT-15 and COLO-205 cells were maintained in RPMI-1640 medium, while HCT-116 cells were maintained in McCoy's growth medium. The medium was supplemented with $10 \%$ FBS and $1 \%$ antibiotic-antimycotic solution, and cells were grown at $37^{\circ} \mathrm{C}$ with $95 \%$ humidity in incubator maintaining $5 \% \mathrm{CO}_{2}$.

In vitro tumorigenesis assay. Tumorigenic potential was determined using soft agar colony-forming assay (10). Briefly, a bottom layer containing $0.4 \%$ agar, $1 \mathrm{X}$ growth media and $10 \%$ FBS was prepared in $60-\mathrm{mm}$ culture dishes. An overlay media, containing 1,000 cells in $0.3 \%$ agarose, $1 \mathrm{X}$ growth media and $10 \% \mathrm{FBS}$, was added to each plate in triplicate. The cells were incubated for $3-4$ weeks at $37^{\circ} \mathrm{C}$ in a humidified $\mathrm{CO}_{2}$ incubator and given fresh media every 4th day. Colony formation was observed after 3 weeks of plating; bright field images (at 10x magnification) were captured using the CMOS camera application in ChemiDoc Imaging system (Bio-Rad Laboratories, Inc.). Clones were counted and quantified as relative colony-forming units between $\mathrm{CRC}$ cells.

Transwell cell migration assay. The migratory capacity of metastatic cells was measured by their ability to invade through extracellular matrix (ECM), following a previously described protocol (12). Cells $(\sim 5,000)$ were plated in triplicates in $8-\mu \mathrm{m}$ pore-sized cell culture inserts (BD Labware; BD Biosciences) and supplemented with media without serum.
These cell inserts were positioned in 12-well plates containing media with $10 \% \mathrm{FBS}$, followed by incubation for $12-16 \mathrm{~h}$ at $37^{\circ} \mathrm{C}$ in a $5 \% \mathrm{CO}_{2}$ incubator. Migration of cells was visualized by staining the cells with Hema 3 staining following manufacturer's instructions (Thermo Fisher Scientific, Inc.) and images were captured at $100 \mathrm{x}$ magnification using a microscope (Nikon Eclipse TE2000; Nikon Corporation). Total number of stained and migrated cells were counted, and calculated as relative migration units between CRC cells.

Cell viability measurements. A total of $\sim 5 \times 10^{5}$ cells $/ \mathrm{ml}$ were seeded in triplicates in 12-well plates in culture medium and incubated at $37^{\circ} \mathrm{C}$ for $24 \mathrm{~h}$. Cells were treated with different agents at multiple concentrations [rotenone, 0.05-200 $\mu \mathrm{M}$; paraquat, 0.025-20 mM; antimycin, 0.25-20 $\mu \mathrm{M}$; oligomycin, 5-100 $\mu \mathrm{M} ; \mathrm{H}_{2} \mathrm{O}_{2}, 0.025-2 \mathrm{mM}$; N-acetyl cysteine (NAC), $5 \mathrm{mM}$; all purchased from Sigma-Aldrich) followed by $24 \mathrm{~h}$ incubation at $37^{\circ} \mathrm{C}$. Cell viability assay was performed by staining the cells with trypan blue $(0.4 \%)$ for $3 \mathrm{~min}$ at room temperature and counting by haemocytometer. Bright field images of cells were captured at X100 magnification.

Blue native gel electrophoresis and C-I activity assay. Blue native poly acrylamide gel electrophoresis (BN-PAGE) was performed following optimized protocol as published previously (18). Cultured cells were harvested and centrifuged (at $100 \mathrm{x} \mathrm{g}$ for $5 \mathrm{~min}$ at room temperature), and the pellet was re-suspended in $0.5 \mathrm{ml}$ ice-cold $\mathrm{HB}$ buffer (50 mM KPO4; pH: 7.4; 1 mM EDTA; 2.5\% glycerol; $250 \mathrm{mM}$ sucrose) containing protease inhibitor cocktail (Sigma-Aldrich). Cells were disrupted using a dounce homogenizer at $4^{\circ} \mathrm{C}$ for $5 \mathrm{~min}$ and enriched for mitochondria via differential centrifugation at $4^{\circ} \mathrm{C}$ (initial spin at $500 \mathrm{x}$ g for $5 \mathrm{~min}$ where the supernatant was removed, and respun to pellet the mitochondria at $10,000 \mathrm{x} \mathrm{g}$ for $5 \mathrm{~min}$ ). The mitochondrial pellet was washed twice and re-suspended in a final protein concentration of $2-5 \mathrm{mg} / \mathrm{ml}$ in HB buffer. Optimal solubility of mitochondrial super-complexes was achieved using optimized concentration of $8 \mathrm{mg}$ digitonin $/ \mathrm{mg}$ of protein in HB buffer without EDTA. The samples were incubated on ice for $20 \mathrm{~min}$ in a coomassie blue solution (5\% coomassie blue G-250 in 750 mM 6-aminocaproic acid) to a ratio of 1:30 v/v. The supernatant (total of $80 \mu \mathrm{g}$ protein) was then run on a $3-12 \%$ Native PAGE (Novex Bis-Tris gel) for $4 \mathrm{~h}$ at $80 \mathrm{~V}$ and $4^{\circ} \mathrm{C}$ in the buffer provided by the supplier (Invitrogen; Thermo Fisher Scientific, Inc.), to resolve the mitochondrial complexes, and the resulting gels were stained with Bio-safe coomassie R-250 (Bio-Rad Laboratories, Inc.) for $30 \mathrm{~min}$ at room temperature.

In parallel, a similarly run gel without staining was used for the gel activity assay for C-I following a previously published protocol (19). Both the stained and activity gels were scanned and analyzed using ImageJ software (version 1.8.0; National Institutes of Health), to determine the relative band intensities, which were normalized with total mitochondrial protein levels and calculated as fold change relative to HT-29 bands. Equal loading ( $80 \mu \mathrm{g}$ ) of mitochondrial protein was confirmed by running a similar aliquot of mitochondrial extract on a separate $12 \%$ denaturing gel and western blotting with mitochondrial voltage-dependent anion channel protein (cat. no 4661, Cell Signaling Technology, Inc.). 
Western blotting. Protein samples were extracted using RIPA buffer (Cell Signaling Technology, Inc.) and the concentration of protein was determined using a BCA Protein assay kit (Pierce; Thermo Fisher Scientific, Inc.). The samples $(30 \mu \mathrm{g})$ were electrophoresed on $12 \%$ SDS-PAGE at $120 \mathrm{~V}$ for $2 \mathrm{~h}$. The resolved proteins were transferred on PVDF membrane and blocked with $5 \%$ non-fat dry milk in TBS-0.5\% Tween-20 (TBS-T) for $1 \mathrm{~h}$ at room temperature. The membrane was incubated with primary antibodies at dilution of $1: 1,000$, overnight at $4^{\circ} \mathrm{C}$ following manufacturer's instructions (Cell Signaling Technology, Inc.). The antibodies against pAKT-Thr (308) (cat. no. 13038), p-AKT-Ser (473) (cat. no. 4060), total AKT (cat. no. 4691), Actin (cat. no. 4970), HIF1- $\alpha$ (cat. no. 36169), cMyc (cat. no. 18583), GAPDH (cat. no. 5174), SOD1 (cat. no. 37385), Beclin-1 (cat. no. 3495) and ATG5 (cat. no. 12994) were purchased from Cell Signaling Technology, Inc. The membrane was washed thrice with TBS-T and then incubated with anti-rabbit IgG horseradish peroxidase-conjugated secondary antibody (cat. no. 7074; Cell Signaling Technology, Inc.) at 1:5,000 dilution. Specific bands were detected using super signal west pico-chemi-luminescent substrate kit (Thermo Fisher Scientific, Inc.) and imaged on a ChemiDoc Imaging system (Bio-Rad Laboratories, Inc.). Experiments were performed twice or thrice, and one of the representative images was analyzed for densitometry using ImageJ (version 1.8.0; National Institutes of Health).

\section{Mitochondrial functional analysis.}

Reactive oxygen species measurement. To measure cellular ROS levels, cell-permeant 2',7'-dichlorodihydrofluorescein diacetate $\left(\mathrm{H}_{2}\right.$ DCFDA $)$ dye was used as per manufacturer's instructions (Invitrogen; Thermo Fisher Scientific, Inc.). Briefly, $1 \times 10^{6}$ live cells were re-suspended in Hank's buffered salt solution (HBSS) with $\mathrm{H}_{2}$ DCFDA $(10 \mu \mathrm{M})$ and Hoechst-33342 $(10 \mu \mathrm{g} / \mathrm{ml})$, and incubated at $37^{\circ} \mathrm{C}$ for $15 \mathrm{~min}$. Cells were then washed, centrifuged at $100 \mathrm{x} \mathrm{g}$ for $5 \mathrm{~min}$ at room temperature and the resulting pellet was re-suspended in PBS. The fluorescence intensity was measured using HT-BioTek fluorescence plate reader at Excitation/Emission (Ex/Em): 495/529 nm for $\mathrm{H}_{2}$ DCFDA and $350 / 497 \mathrm{~nm}$ for Hoechst-33342 at $37^{\circ} \mathrm{C}$.

To measure mitochondrial superoxide levels, mitochondrial specific superoxide indicator dye MitoSOX ${ }^{\mathrm{TM}}$ Red (Invitrogen; Thermo Fisher Scientific, Inc.) was used. Equal number of cells $\left(1 \times 10^{6}\right)$ were re-suspended in HBSS buffer with MitoSOX ${ }^{\mathrm{TM}} \operatorname{Red}(5 \mu \mathrm{M})$ and Hoechst-33342 $(10 \mu \mathrm{g} / \mathrm{ml})$, and incubated at $37^{\circ} \mathrm{C}$ for $15 \mathrm{~min}$. Cells were washed, and the fluorescence (MitoSOX ${ }^{\mathrm{TM}}$ Red; Ex/Em, 510/580 nm) was measured using HT-BioTek fluorescence plate reader. Relative values for both measurements were calculated after normalizing with Hoechst-33342 fluorescence. All the experiments were performed in triplicates, and the results are presented as relative mean fluorescence intensity.

ATP measurement. Total ATP content was measured using luciferase-based ATP determination kit according to manufacturer's instructions (Invitrogen; Thermo Fisher Scientific, Inc.). For ATP measurement, $1 \times 10^{6}$ cells were harvested, centrifuged at $100 \mathrm{x} \mathrm{g}$ for $5 \mathrm{~min}$ at room temperature and re-suspended in $100 \mu \mathrm{l}$ buffer $(25 \mathrm{mM}$ Tris; $\mathrm{pH} 7.4 ; 150 \mathrm{mM}$ EDTA). The re-suspended cells were boiled at $100^{\circ} \mathrm{C}$ for
$5 \mathrm{~min}$, followed by centrifugation at $10,000 \times \mathrm{g}$ for $5 \mathrm{~min}$ at room temperature. The supernatant was collected, added to the luciferin-luciferase mixture and luminescence was measured in BioTek Synergy HT Multi-detection Microplate reader. The ATP concentration was determined using a standard ATP/luminescence curve ranging from 0.001-10 mM ATP, normalized to total protein and calculated as relative fold change between CRC cells.

Mitochondrial Membrane Potential (MMP) measurement. Similar to ATP measurement, $1 \times 10^{6}$ cells were incubated with $200 \mathrm{nM}$ MMP indicator dye tetra-methyl-rhodamine methyl ester perchlorate (TMRM) for $15 \mathrm{~min}$ at $37^{\circ} \mathrm{C}$. Cells were washed and counterstained with Hoechst-33342 $(10 \mu \mathrm{g} / \mathrm{ml})$ for $5 \mathrm{~min}$ at $37^{\circ} \mathrm{C}$. Fluorescence was recorded for TMRM (Ex/Em, $540 / 575 \mathrm{~nm}$ ) using a fluorescence plate reader. Relative values for both measurements were calculated after normalizing to Hoechst-33342 fluorescence. All experiments were performed in triplicates, and the results are presented as relative mean fluorescence intensity.

Mitochondrial DNA (mtDNA) copy number measurement. Total DNA was isolated from $1 \times 10^{6} \mathrm{CRC}$ cells using DNeasy kit (Qiagen China Co., Ltd.). A total of $20 \mathrm{ng}$ of DNA was used for quantitative PCR (qPCR) for mtDNA copy number determination using the Fast SYBR Green Master mix (Applied Biosystems; Thermo Fisher Scientific, Inc.) on a 7900HT Fast Real-Time PCR system (Applied Biosystems; Thermo Fisher Scientific, Inc.. The steps were as follows: $95^{\circ} \mathrm{C}$ For $10 \mathrm{~min}$, followed by 40 cycles of $95^{\circ} \mathrm{C}$ for $15 \mathrm{sec}$ and $60^{\circ} \mathrm{C}$ for $1 \mathrm{~min}$. Quantitation of mtDNA copy number relative to nuclear DNA was done by amplifying mtDNA (human tRNA leucine1, transcription terminator and 5S-like sequence), and nuclear reference gene (18s ribosomal DNA) as previously described (20). The primer sequences were: mtDNA (Human-tRNA leucine 1, transcription terminator and 5S-like sequence), forward: 5'-CACCCAAGAACAGGGTTTGT-3' and reverse: 5'-TGGCCATGGGTATGTTGTTAA-3'; nDNA (18s ribosomal DNA), forward: 5'-TAGAGGGACAAGTGG CGTTC-3' and reverse: 5'-CGCTGAGCCAGTCAGTGT-3'. Relative mtDNA copy number was calculated with normalization to the nuclear DNA (18s ribosomal DNA) copy number using $2^{-\Delta \Delta \mathrm{Cq}}$ method (21).

Reverse transcription-quantitative PCR (RT-qPCR). For gene expression studies, RNA was isolated from $1 \times 10^{6}$ non-treated cells or treated with rotenone $(100 \mu \mathrm{M})$ /paraquat $(10 \mathrm{mM})$ for different time points (0, 3, 6 and $12 \mathrm{~h}$ ), using RNeasy kit (Qiagen China Co., Ltd.). A total of $1 \mu \mathrm{g}$ RNA was reversed transcribed into cDNA using the QuantiTect Reverse Transcription kit (Qiagen China Co., Ltd.) at $42^{\circ} \mathrm{C}$ for $15 \mathrm{~min}$, and $95^{\circ} \mathrm{C}$ for $3 \mathrm{~min}$. Subsequently qPCR was performed using Fast SYBR Green Master mix following similar PCR conditions as aforementioned. The list of primers used for RT-qPCR of the various genes (PGC1- $\alpha$, TFAM, $\beta$-actin, AKT-1, HIF-1 $\alpha$, cMyc, Survivine, SLC2A1, CA-9, VEGF) is presented in Table SI with relevant references (22-25). In addition, qPCR of C-I subunit genes was performed using mtDNA encoded ND-1,-2,-4, -4L and -6 gene primers as reported by Salehi et al (26). Relative gene expression of target genes 

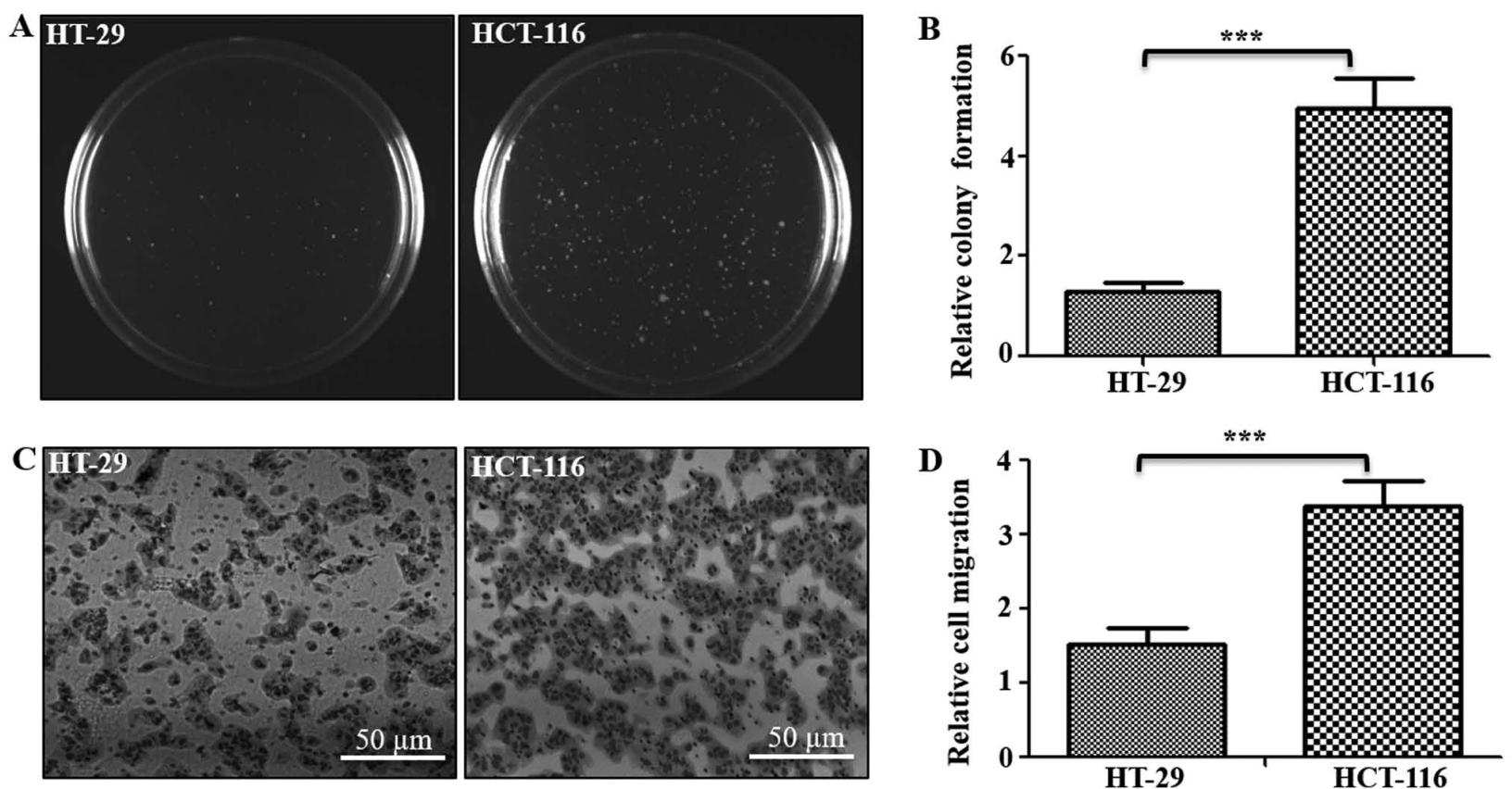

Figure 1. Tumorigenic and metastatic potential of colorectal cancer cells. (A) Soft agar assay was performed to measure the tumorigenic potential of cells. The colonies were imaged and counted after 3 weeks, and representative images of one of the three experiments are shown. (B) Total number of colonies were counted and represented as relative colony units. (C) Cell migration was analyzed using Transwell assay (triplicate/line), and cells that migrated to the lower surface were stained and imaged. Scale bar, $50 \mu \mathrm{m}$. (D) Number of cells migrated and stained was counted and represented relative migration units. ${ }^{* * * *} \mathrm{P}<0.001$ vs. HT-29 cells.

was normalized to $\beta$-actin expression (reference gene) using $2^{-\Delta \Delta \mathrm{Cq}}$ method (21).

Statistical analysis. Graphs were prepared and analyzed using GraphPad Prism 5 software (GraphPad Software, Inc.). Data in graphs are presented as the mean \pm SEM. Experiments were performed at least thrice with $\geq 3$ replicates for each condition. Morphological images were representative of $\geq 3$ independent experiments with similar results. Significant statistical differences were measured using unpaired Student's t-test or one-way ANOVA followed by Dunnett's post hoc test for comparisons between treatment and control groups or by Tukey's test for comparisons among multiple groups. $\mathrm{P}<0.05$ was considered to indicate a statistically significant difference.

\section{Results}

Properties of cell lines. To study the role of mitochondrial functions in the metastatic potential of CRC cells, low metastatic HT-29 and high metastatic HCT-116 CRC lines were used. To confirm whether these cells demonstrate their respective cancer properties, the tumorigenic and metastatic potentials were examined using soft agar and Transwell assays, respectively (Fig. 1). Results of soft agar assay indicated that HCT-116 cells formed 23.8 -fold higher numbers of clones on soft agar compared with HT-29 cells (Fig. 1A and B). Similarly, Transwell assay results identified that the number of cells that migrated through the ECM matrix were $\sim 2.3$-fold higher in HCT-116 cells compared with HT-29 cells (Fig. 1C and D). Thus, these assays confirmed the tumorigenic and metastatic potentials of both cells, indicating HT-29 cells as low tumorigenic and metastatic, with HCT-116 cells as highly tumorigenic and metastatic in nature.

Resistance to $C$-I inhibition in low metastatic cells. In mitochondria, C-I and Complex III (C-III) are considered as the major producers of superoxide anions among $\mathrm{RC}$ complexes, and inhibition of these complexes results in an increased mitochondrial oxidative stress (27-29). The present study investigated the effect of mitochondrial oxidative stress via pharmacological inhibition of these complexes by measuring cellular viability of metastatic cells. Rotenone is a C-I inhibitor that acts by blocking the transfer of electrons from iron-sulfur centers in C-I to ubiquinone, which results in the inhibition of OXPHOS, limited ATP production and increased free radical production (30). Similarly, antimycin-A is a C-III inhibitor that binds to the quinone reduction site of C-III, leading to increased superoxide production (31). Cells were treated with different concentrations of rotenone and antimycin-A to measure the effect of C-I and C-III inhibition on cellular viability, respectively. It was found that both HT-29 and HCT-116 cells were tolerant to lower concentrations of rotenone $(0-20 \mu \mathrm{M})$. However, at $>20 \mu \mathrm{M}$ concentration, HCT-116 cells demonstrated increased sensitivity and cell death, while HT-29 cells had resistance up to $200 \mathrm{mM}$ (Fig. 2A and B). With regards to antimycin, both cell lines exhibited a similar trend of declined viability at $\geq 5 \mu \mathrm{M}$ (Fig. 2C and D).

Since electron transfer via $\mathrm{RC}$ complexes is associated with ATP production, the effect of ATP synthase [Complex-V (C-V)] inhibition using oligomycin was examined. Oligomycin is an inhibitor of $\mathrm{C}-\mathrm{V}$ that functions by inducing conformational change in the $\mathrm{F}_{0}$ subunit and impairs binding with substrate at the catalytic sites, leading to ATP depletion (32). Both 
A

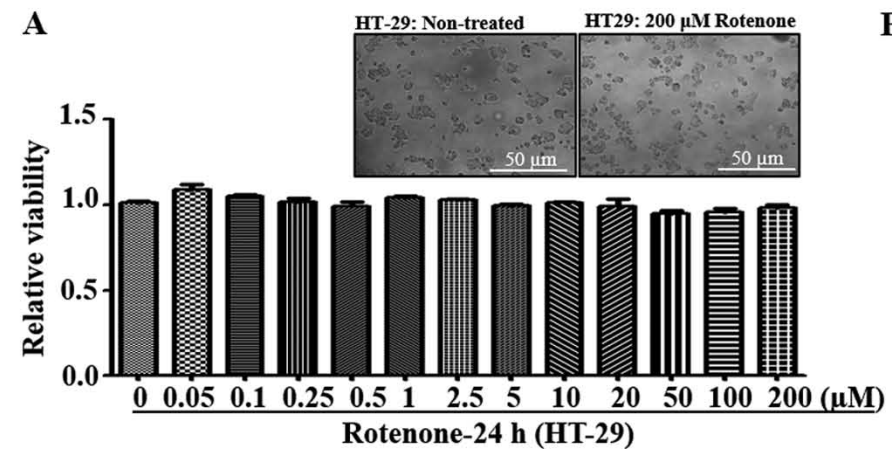

C

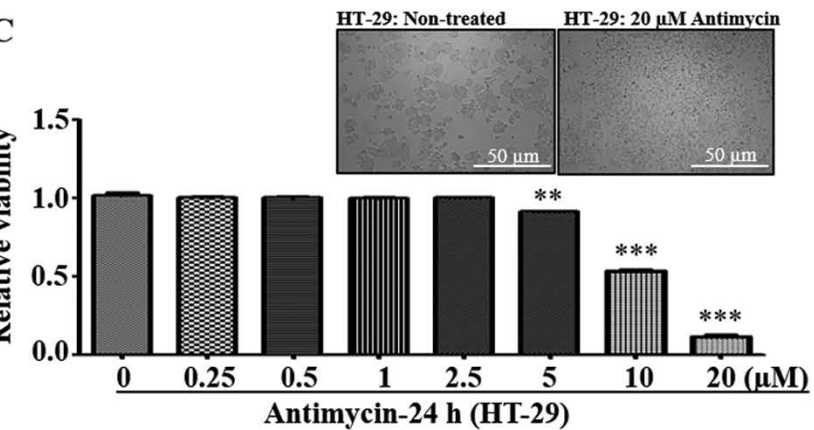

$\mathbf{E}$

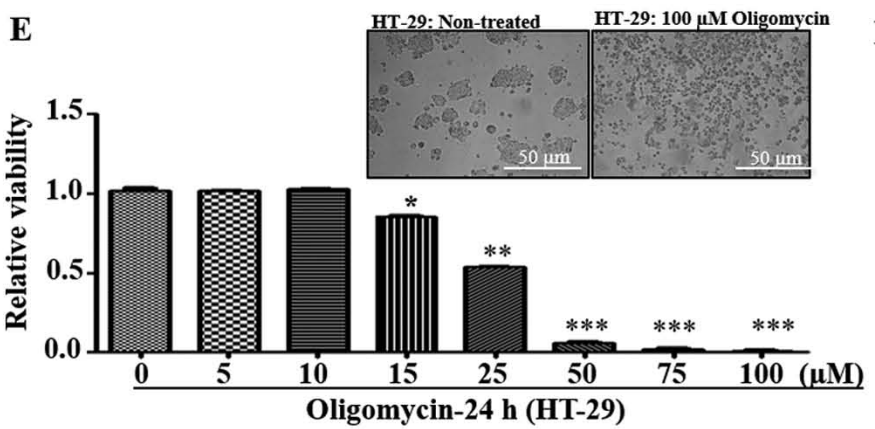

B

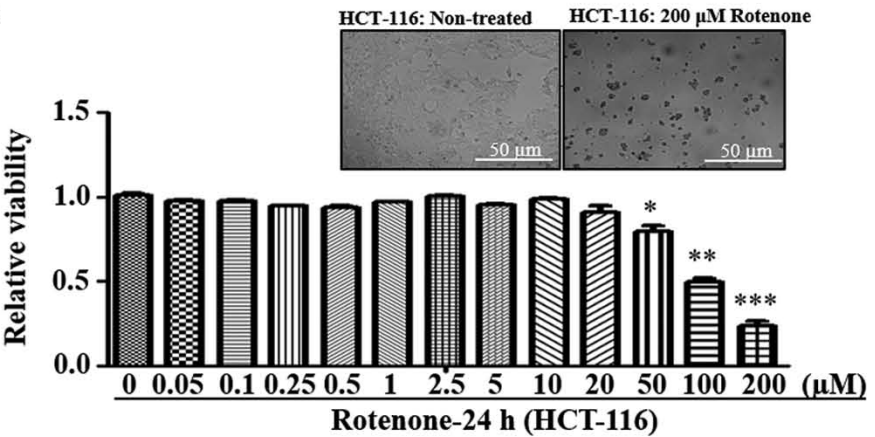

D
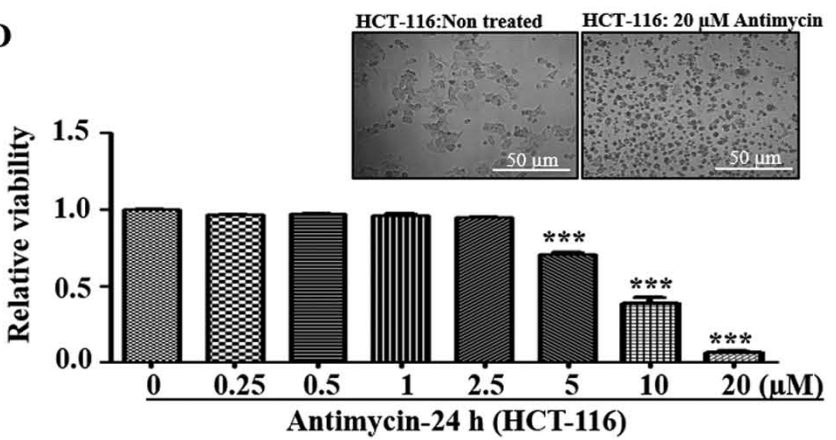

F

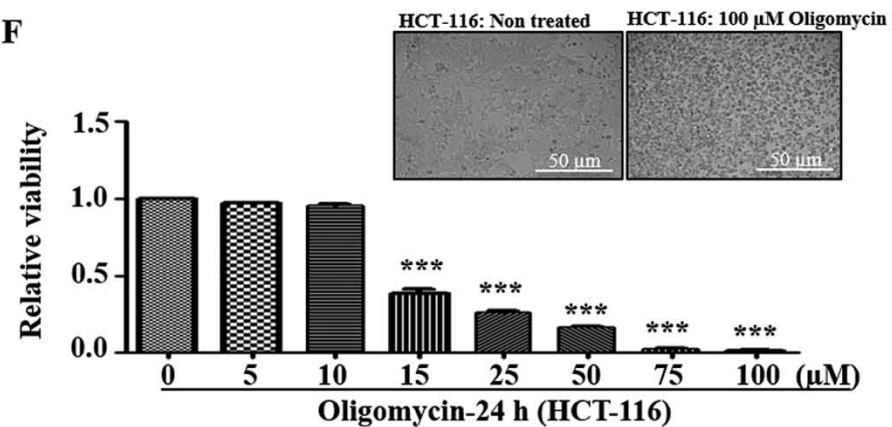

Figure 2. Effect of mitochondrial respiratory chain inhibitors on cell viability. (A) HT-29 and (B) HCT-116 cells were treated with varying concentrations of the Complex I inhibitor rotenone $(0.05-200 \mu \mathrm{M})$ for $24 \mathrm{~h}$. (C) HT-29 and (D) HCT-116 cells were treated with varying concentrations of the Complex III inhibitor antimycin $(0.25-20 \mu \mathrm{M})$ for $24 \mathrm{~h}$. (E) HT-29 and (F) HCT-116 cells were treated with varying concentrations of the Complex V inhibitor oligomycin (5-100 $\mu \mathrm{M})$ for $24 \mathrm{~h}$. Bright field images of cells were captured at x100 magnification, and representative images for control and treatment are provided to indicate morphological changes at the highest concentration for various inhibitors. Cellular viability was measured via trypan Blue staining and calculated relative to non-treated cells. ${ }^{*} \mathrm{P}<0.05,{ }^{* *} \mathrm{P}<0.01$ and ${ }^{* * *} \mathrm{P}<0.001$ vs. $0 \mu \mathrm{M}$ of rotenone/antimycin/oligomycin.

HT-29 and HCT-116 cell lines demonstrated similar sensitivity to $\mathrm{C}-\mathrm{V}$ inhibition, with decreased viabilities at $\geq 15 \mu \mathrm{M}$ oligomycin concentrations (Fig. 2E and F). Overall, in response to different RC inhibitors, low metastatic HT-29 cells had significant resistance towards rotenone treatment compared with high metastatic cells, indicating possible C-I abnormalities.

Resistance of low metastatic cells to $\mathrm{C}$-I inhibition was assessed via repeatedly measuring cell viability after paraquat treatment, another C-I inhibitor. Paraquat is reduced by C-I to form paraquat cation radicals, which react with oxygen to form superoxide (28). C-I inhibition was similar in both the inhibitors (rotenone and paraquat); HT-29 cells were resistant to higher concentration of paraquat compared with HCT-116 cells, and could tolerate concentrations up to $20 \mathrm{mM}$ without decreasing cell viability (Fig. S1). Thus, the investigation of RC inhibitors on cell viability suggested that low metastatic HT-29 cells were tolerant to higher concentrations of C-I inhibitors (Rotenone and paraquat) compared with high metastatic cells, which indicated a compromised or non-functional C-I in HT-29 cells.
Upregulated C-I and mitochondrial functions in high metastatic cells. In order to investigate potential differences in C-I functionality between low and high metastatic cells that may contribute to their sensitivity to C-I inhibition, C-I assembly and activity were analyzed using BN-PAGE and C-I in-gel activity assay, respectively. These measurements were performed in the isolated mitochondria from low and high metastatic cells. BN-PAGE results demonstrated an enhanced C-I assembly via increased expression of C-I specific band in HCT-116 cells, while its corresponding band was almost absent in HT-29 cells (Fig. 3A and C). Similarly, functional activity of assembled C-I was higher in HCT-116 compared with HT-29 cells as indicated by increased staining of C-I band in C-I specific in-gel activity assay (Fig. 3B and D). Equal loading of mitochondrial preparation for BN-PAGE/in-gel assay from these cells was confirmed by western blotting of similar aliquot with mitochondrial marker protein VDAC as loading control (Fig. 3E).

To assess whether this upregulation of C-I was a common feature in other high metastatic cells, two different CRC 
$\mathbf{A}$

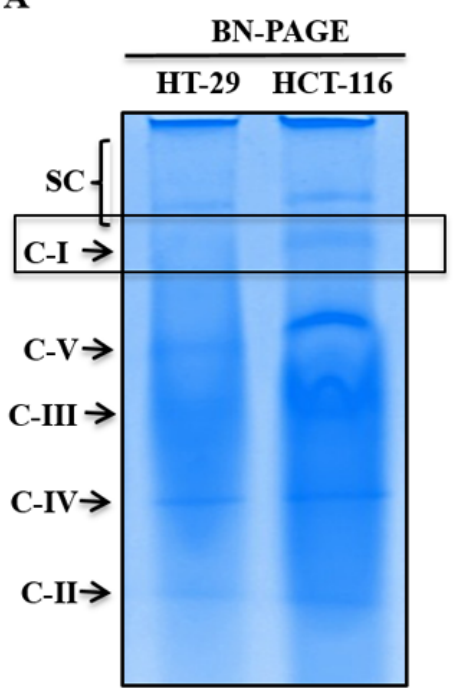

B

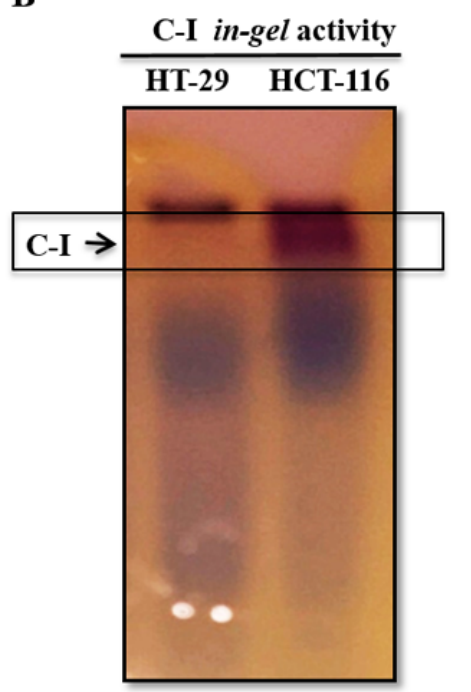

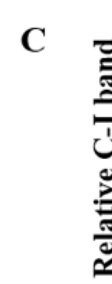

D
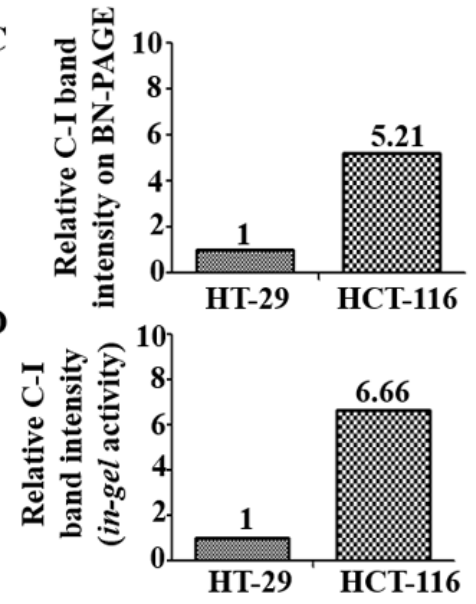

$\mathbf{E}$

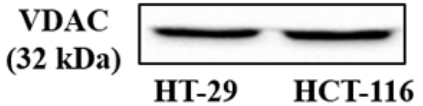

Figure 3. Mitochondrial C-I assembly and activity analysis. (A) BN-PAGE was performed in the isolated mitochondrial preparation of cultured cells. (B) C-I activity was measured using in gel C-I activity assay. Relative band intensities of C-I on (C) BN-PAGE and (D) in-gel assay were quantitated using ImageJ and normalized with total mitochondrial protein loaded $(80 \mu \mathrm{g})$. (E) Equal loading of mitochondrial proteins is shown by immunoblotting results of an aliquot of the same samples used for BN-PAGE/in-gel assay, with mitochondrial marker protein VDAC. C-, complex; VDAC, Voltage-dependent anion channel; BN-PAGE, Blue native polyacrylamide gel electrophoresis.

cells, HCT-15 and COLO-205, with low and high metastatic potential, respectively (33), were used. C-I functionality was determined by measuring the gene expression profile of mtDNA encoded C-I genes. mtDNA encodes seven C-I subunit genes (ND-1, -2, -3, -4, -4L, -5 and -6) (13), and RT-qPCR analysis was performed to detect the mRNA expression of 5 of these subunit genes (except ND-3 and ND-5 genes) in metastatic cells. Significantly higher expression levels of C-I genes were identified in high metastatic COLO-205 cells, compared with low metastatic HCT-15 cells (Fig. S2A), which confirmed C-I upregulation in high metastatic cells.

C-I is the major entry point for electrons in electron transfer chain, and its inhibition may cause changes in free radicals and mitochondrial functions $(10,12)$. Therefore, to investigate the status of mitochondrial functions in these cells, ROS, mitochondrial superoxides, ATP and MMP levels were measured in HT-29 and HCT-116 cells. Total ROS levels were measured using $\mathrm{H}_{2}$ DCFDA, which remains non-fluorescent until oxidized to the highly fluorescent 2',7'-dichlorofluorescein radicals. Compared with HT-29 cells, HCT-116 cells had significantly lower levels ( 0.76-fold lower) of total ROS (Fig. 4A). Furthermore, mitochondrial superoxide levels were measured using indicator dye MitoSOX ${ }^{\mathrm{TM}}$ Red, which is oxidized by mitochondrial superoxides. While a decrease in mitochondrial superoxide levels was observed in HCT-116 cells, it was not significantly different compared with HT-29 cells (Fig. 4B). Measurement of total ATP in these cells identified a 0.36 -fold significantly higher ATP content in HCT-116 compared with HT-29 cells (Fig. 4C). However, there was no significant difference in MMP levels (Fig. 4D). Similar changes in mitochondrial functions were observed when examined in additional CRC cells (Fig. S2B).

Therefore, the results suggested that C-I assembly and activity were worse in low metastatic cells, while C-I was upregulated in high metastatic cells, which may contribute to improved mitochondrial functions, such as decreased oxidative stress, increased ATP levels and enhanced cellular proliferation.

Increased sensitivity to oxidative stress in high metastatic cells. Various chemotherapeutic agents can induce cell death in tumor cells via generation of oxidative stress. To further evaluate whether the metastatic potential of CRC cells depends upon changes in C-I and mitochondrial functionality via their response to higher oxidative stress, their susceptibility towards a general oxidative stress agent, $\mathrm{H}_{2} \mathrm{O}_{2}$, was examined. $\mathrm{H}_{2} \mathrm{O}_{2}$ is a well-studied oxidative stress-inducing agent, where transient exposure triggers apoptosis in a variety of mammalian cells (34-37). Thus, low and high metastatic cells were treated with varied concentration of $\mathrm{H}_{2} \mathrm{O}_{2}$, and their viability was measured (Fig. 5A and B). In HT-29 cells, no significant cell death was observed from $0.025-0.5 \mathrm{mM} \mathrm{H}_{2} \mathrm{O}_{2}$ concentrations; a significant decrease in viability was observed at $\geq 1 \mathrm{mM}$ (Fig. 5B). Compared with HT-29, HCT-116 cells demonstrated a higher sensitivity to $\mathrm{H}_{2} \mathrm{O}_{2}$-induced cell death at $\geq 0.1 \mathrm{mM}$; with a $\sim 0.40$-fold viability at $0.25 \mathrm{mM}$, and $<0.05$-fold viability at $\geq 0.5 \mathrm{mM}$ concentrations of $\mathrm{H}_{2} \mathrm{O}_{2}$ (Fig. $5 \mathrm{~A}$ and $\mathrm{B}$ ).

The general antioxidant NAC was used in combination with $\mathrm{H}_{2} \mathrm{O}_{2}$, and cellular viability was measured to examine whether the cells differed in their response to recovery after oxidative stress. Inhibitory concentrations of $\mathrm{H}_{2} \mathrm{O}_{2}$ for HT-29 cells (1-1.5 mM H $\mathrm{m}_{2} \mathrm{O}_{2}$ ) and for HCT-116 cells (0.25-0.5 mM H $\left.\mathrm{H}_{2} \mathrm{O}_{2}\right)$ were used with or without $5 \mathrm{mMNAC}$, and cellular viability was measured. It was identified that, with regards to HT-29 cells, antioxidant treatment significantly restored the viability, while HCT-116 cells demonstrated only partial recovery at the given inhibitory concentrations (Fig. 5C and D). Therefore, these results suggested that low metastatic cells were more tolerant to higher oxidative stress, and high metastatic cells were more sensitive to oxidative stress-induced cell death. 

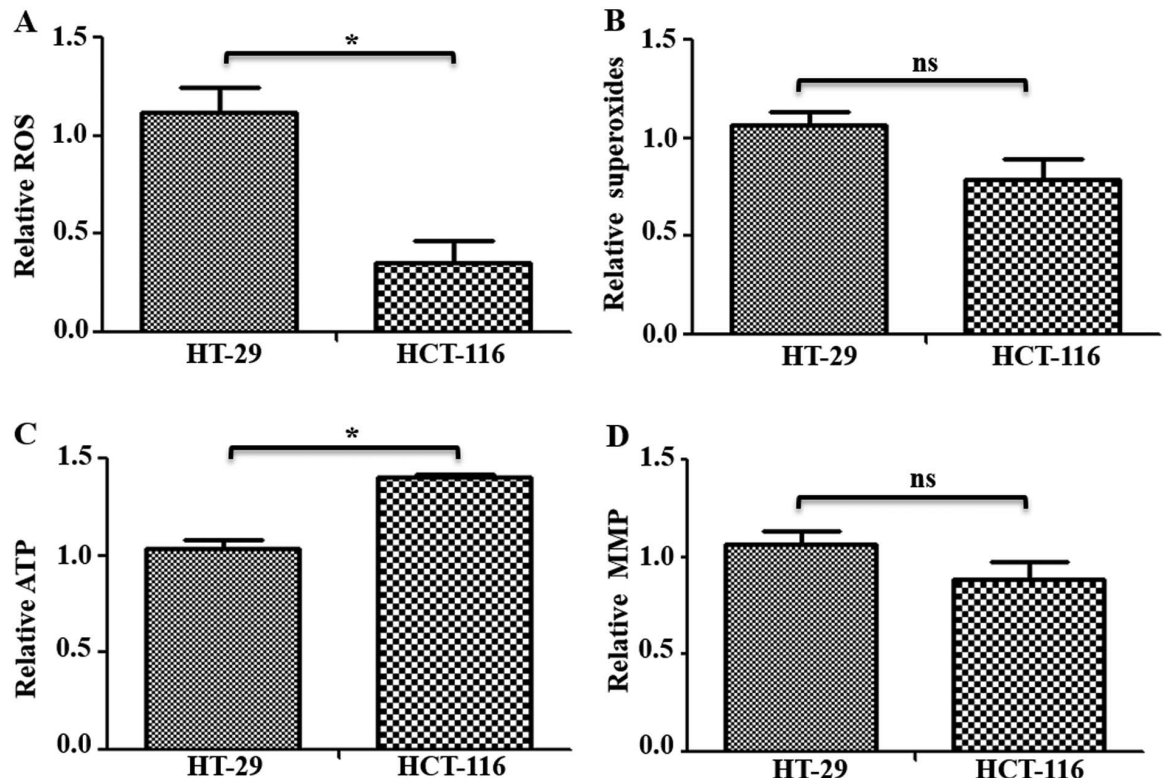

Figure 4. Functional status of mitochondria in colorectal cancer cells. Cells $\left(\sim 1 \times 10^{6}\right)$ were used for mitochondrial functional analysis. (A) Total ROS levels were measured via staining with 2',7'-dichlorodihydrofluorescein diacetate, and (B) mitochondrial superoxide levels were measured using MitoSOX ${ }^{\mathrm{TM}}$ Red staining followed by measurement on fluorescence plate reader. In both cases, cells were counterstained with Hoechst-33342 and used for normalization. (C) Total cellular ATP content was measured in cells with a luciferase-based ATP detection kit, and normalized with total protein levels. (D) MMP was measured after tetramethylrhodamine methyl ester perchlorate staining and normalization using Hoechs- 33342 reading. ${ }^{*} \mathrm{P}<0.05$. ns, not significant; ROS, reactive oxygen species; MMP, Mitochondrial Membrane Potential.
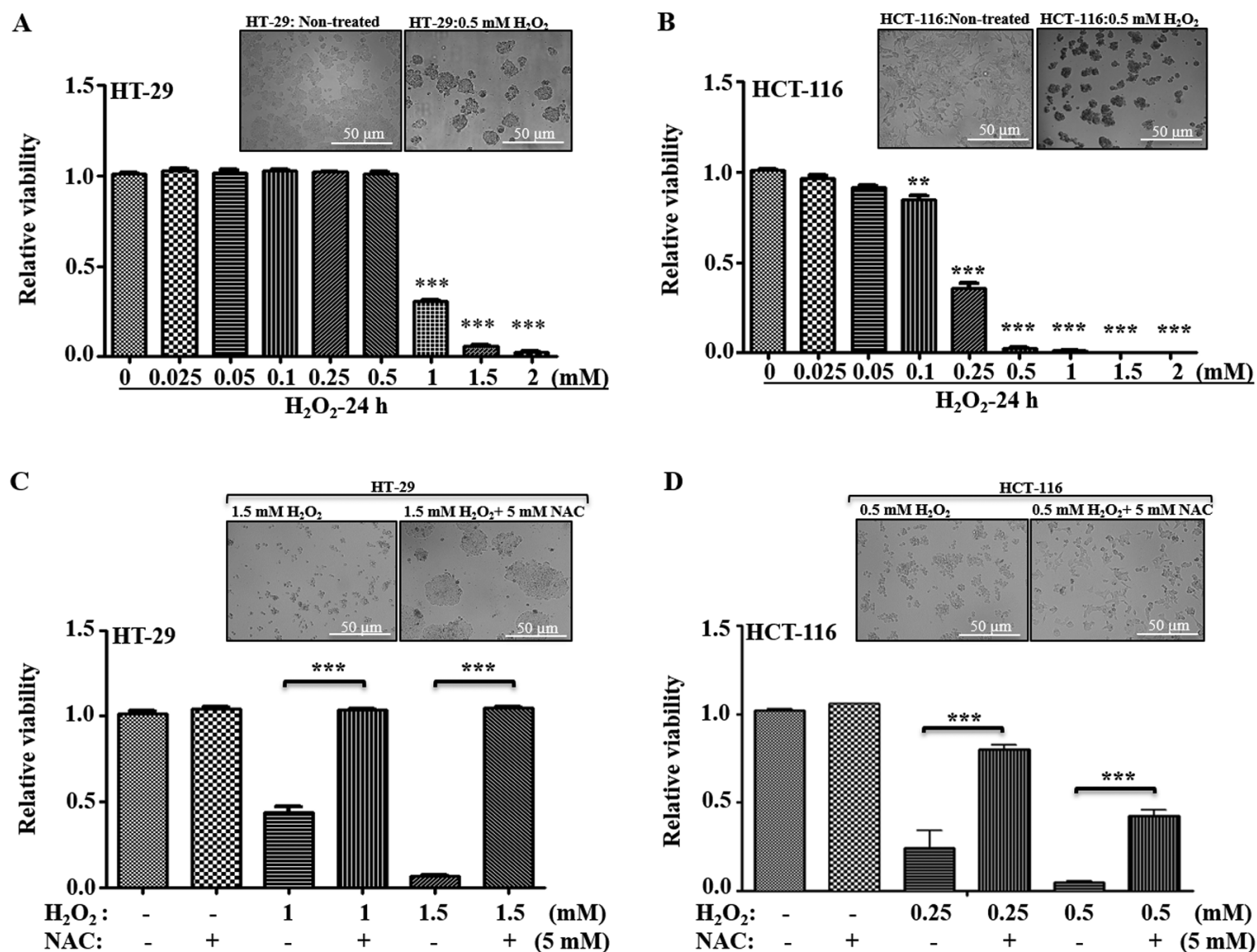

Figure 5. Effect of oxidative stress on cellular viability. (A) HT-29 and (B) HCT-116 cells were treated with varying concentrations of $\mathrm{H}_{2} \mathrm{O}_{2}$ for 24 h, and viability was measured using trypan blue staining. The relative fold changes in the viability was calculated considering control as 1 and compared with viability of cells at different $\mathrm{H}_{2} \mathrm{O}_{2}$ concentrations. Representative bright field images are provided for non-treated and $0.5 \mathrm{mM} \mathrm{H}_{2} \mathrm{O}_{2}$ treated cells. Similarity, the effect of antioxidant (NAC: $5 \mathrm{mM}$ ) on (C) HT-29 and (D) HCT-116 cell survival, with or without the $\mathrm{H}_{2} \mathrm{O}_{2}$ at given concentrations, was measured and compared with their non-treated control. Representative images indicate the recovery of cells after NAC treatment. Scale bar, $50 \mu \mathrm{m} .{ }^{* * *} \mathrm{P}<0.01$ and ${ }^{* * * *} \mathrm{P}<0.001 \mathrm{vs} .0 \mathrm{mM}$ $\mathrm{H}_{2} \mathrm{O}_{2} /$ at indicated $\mathrm{H}_{2} \mathrm{O}_{2}$ concentrations without NAC. NAC, N-acetyl cysteine. 

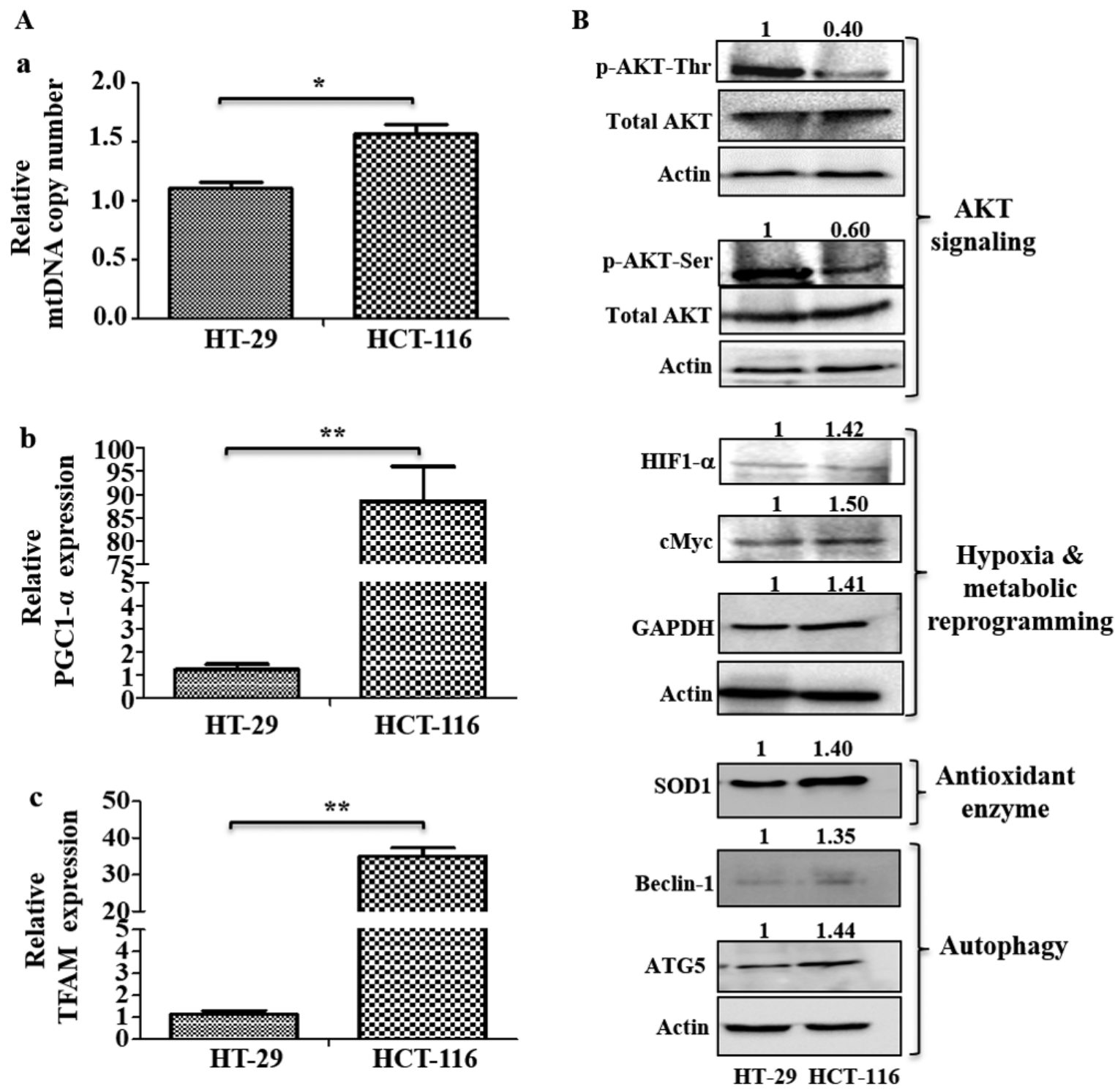

Figure 6. Analysis of mitochondrial biogenesis and signaling pathways. (A) Mitochondrial biogenesis was measured via mtDNA copy number and mRNA expression of mitochondrial biogenesis markers. (A-a) Changes in mtDNA copy number were determined using the SYBR green qPCR method. mRNA expression levels of (A-b) mitochondrial biogenesis marker PGC1- $\alpha$ and (A-c) TFAM were analyzed using reverse transcription-quantitative PCR. (B) Immunoblotting was performed to analyze the expression levels of p-AKT (Ser 478 and Thr 308), HIF1- $\alpha$, cMyc, GAPDH, SOD1, Beclin-1 and ATG5. Values represent relative band intensities of protein that were measured by densitometry, normalized with actin loading control and presented as relative to HT-29. p-AKT (Ser 478 and Thr 308) proteins were normalized with total AKT as well as actin, and other proteins were normalized with $\beta$-actin as loading control. "P<0.05 and ${ }^{* *} \mathrm{P}<0.01$. p-, phosphorylated; HIF1- $\alpha$, hypoxia inducible factor 1 subunit $\alpha$; SOD1, superoxide dismutase 1; ATG5, autophagy related 5; PGC1- $\alpha$, Peroxisome proliferator-activated receptor $\gamma$ coactivator $\alpha$; TFAM, mitochondrial transcription factor A; mtDNA, mitochondrial DNA.

Elevated mitochondrial biogenesis in high metastatic cells. HCT-116 cells had increased C-I function and relatively improved mitochondrial functionality, such as lower levels of ROS and higher ATP levels, compared with HT-29 cells (Figs. 3 and 4A), suggesting an association between effective C-I activity and proliferative signaling pathways, which may contribute to tumor aggressiveness. To understand how high metastatic cells maintain a functional C-I, it was evaluated whether high metastatic cells upregulate the compensatory pathway of mitochondrial biogenesis.

Measurement of mtDNA copy number is an important aspect of mitochondrial biogenesis and reflects the mitochondrial requirements for cellular function (38). Peroxisome proliferator-activated receptor $\gamma$ coactivator $\alpha(\operatorname{PGC} 1-\alpha)$, is a major regulator of the mitochondrial biogenesis, which stimulates transcription of numerous mitochondrial genes via mitochondrial transcription factor A (TFAM), a key regulator in mtDNA replication and transcription (39). The present study measured mtDNA copy number and mitochondrial biogenesis markers to determine mitochondrial requirements during metastasis (Fig. 6A). It was found that HCT-116 cells had higher mtDNA copy numbers compared with HT-29 cells (Fig. 6A-a). RT-qPCR analysis also identified significantly higher expression levels of mitochondrial biogenesis markers (PGC1- $\alpha$ and TFAM) in HCT-116 cells compared with HT-29 cells (Fig. 6A-b and c), indicating an increase in mitochondrial numbers and biogenesis. Similarly, enhanced mitochondrial copy number, biogenesis and transcription were observed in other high metastatic cell lines (Fig. S2C). 

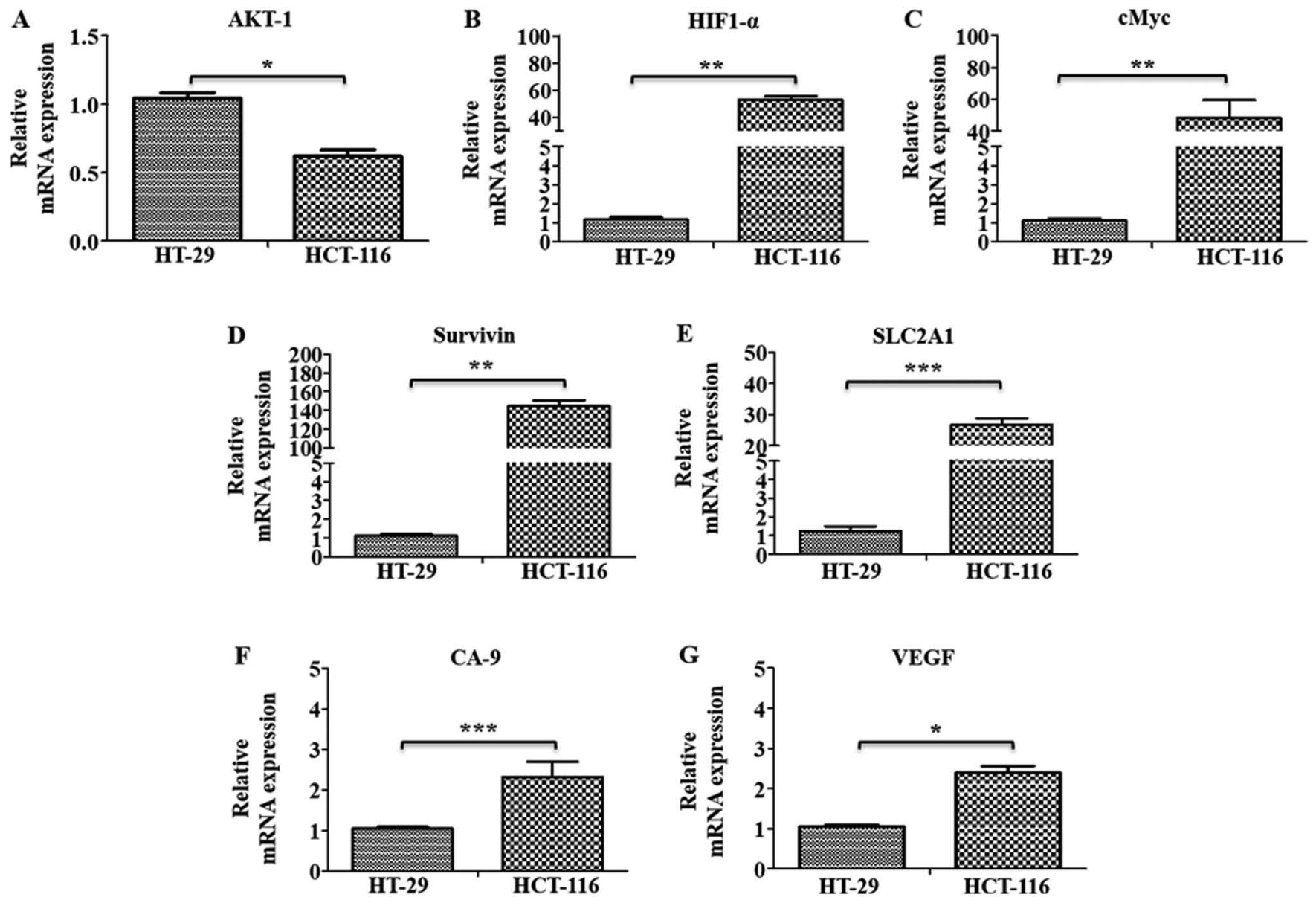

Figure 7. Gene expression profiling of oncogenic and metastatic marker genes. mRNA expression levels of (A) AKT-1, (B) HIF1- $\alpha$, (C) cMyc, (D) Survivin, (E) SLC2A1, (F) CA-9 and (G) VEGF genes were analyzed using SYBR green-based reverse transcription-quantitative PCR. Results are presented as the fold change in the mRNA expression relative to HT-29. ${ }^{*} \mathrm{P}<0.05,{ }^{* *} \mathrm{P}<0.01$ and ${ }^{* * *} \mathrm{P}<0.001$. HIF1- $\alpha$, hypoxia inducible factor 1 subunit $\alpha$; SLC2A1, solute carrier family 2 member 1 ; CA-9, carbonic anhydrase- 9 .

Investigation of metastatic signaling based on metastatic potential. HT-29 cells had relatively higher levels of p-AKT at both Ser473 and Thr308 residues compared with HCT-116 cells (Fig. 6B). However, HCT-116 cells had upregulated expression levels of HIF1- $\alpha$, cMyc, GAPDH, the antioxidant enzyme SOD1 and autophagy markers (Beclin-1 and ATG5), compared with HT-29 cells (Fig. 6B).

The gene expression levels of marker proteins of major pathways, such as oncogenic signaling (AKT-1), hypoxia (HIF1- $\alpha$ ) and metabolic reprogramming (cMyc and GAPDH), were further examined using RT-qPCR analysis, along with the HIF1- $\alpha$ target genes SLC2A1, Survivin, CA-9 and VEGF in these cells. All these markers, (except AKT-1), were found to be significantly upregulated in HCT-116 cells compared with HT-29 cells, indicating their involvement in metastatic progression in these cells (Fig. 7A-G).

Pharmacological inhibition of $C$-I in high metastatic cells blocks metastatic signaling. It was observed that metastatic HCT-116 cells demonstrated a functional C-I and pharmacological inhibition of C-I, and these cells had higher sensitivity to C-I-induced cell death compared with HT-29 cells (Figs. 2B and S1B). It was hypothesized that C-I recovery may serve an important role in the transition to the metastatic stage by enhancing metastatic signaling. Thus, the effect of
C-I inhibition on metastatic signaling in high metastatic cells was also studied. HCT-116 cells were treated with inhibitory concentration of rotenone $(100 \mu \mathrm{M})$, and early time points $(0,3,6$ and $12 \mathrm{~h})$ were selected for measuring gene expression profile of metastatic pathways. It was identified that rotenone treatment significantly decreased the mRNA expression levels of AKT-1, HIF1- $\alpha$, cMyc, SLC2A1, Survivin, GAPDH, CA-9 and VEGF compared with non-treated controls (Fig. 8A-G). In addition, paraquat treatment in these cells with similar conditions resulted in a similar pattern of decreased gene expression levels of these markers, as compared with the control group cells (Fig. S3A-G).

These results suggested that the functional C-I was restored or re-activated in high metastatic cells to maintain or activate oncogenic and metastatic signaling. Moreover, it was indicated that pharmacological inhibition of C-I in high metastatic cells resulted in a decrease in these signaling pathways leading to cell death, thus implicating C-I as a therapeutic target for highly metastatic conditions.

\section{Discussion}

Cancer metastasis includes the migration, invasion and survival of cancer cells in the circulation, followed by their proliferation at distal sites (40). Moreover, this is a highly 

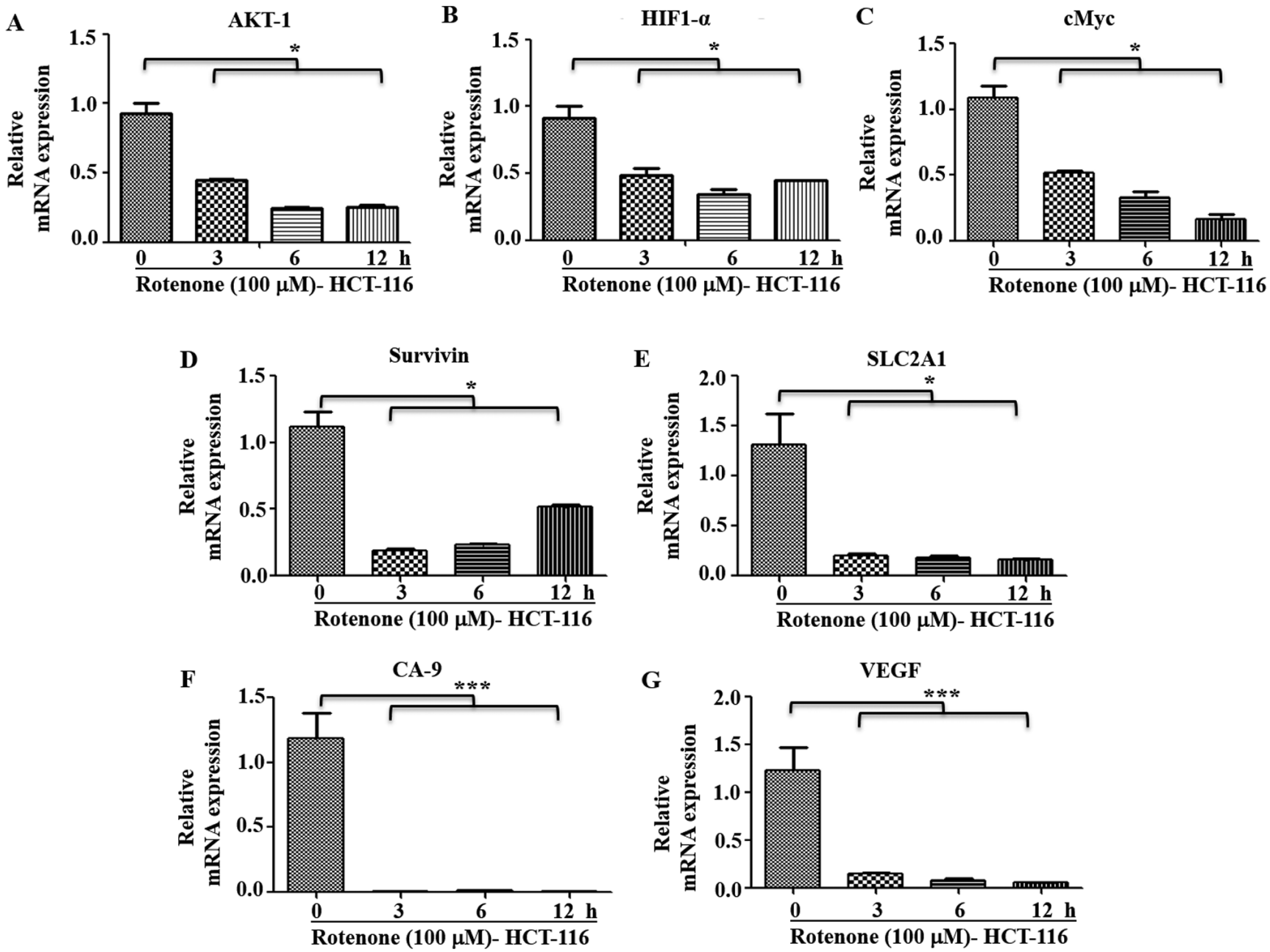

Figure 8. Effect of C-I inhibition on metastatic signaling. HCT-116 cells were treated with rotenone $(100 \mu \mathrm{M})$ for indicated time points, and RNA was used for reverse transcription-quantitative PCR. mRNA expression levels of (A) AKT-1, (B) HIF1- $\alpha$, (C) cMyc, (D) Survivin, (E) SLC2A1, (F) CA-9 and (G) VEGF genes were analyzed using SYBR green dye. Fold changes were calculated relative to non-treated control at 0 h. ${ }^{*} \mathrm{P}<0.05$ and ${ }^{* * *} \mathrm{P}<0.001$. HIF1- $\alpha$, hypoxia inducible factor 1 subunit $\alpha$; SLC2A1, solute carrier family 2 member 1; CA-9, carbonic anhydrase-9.

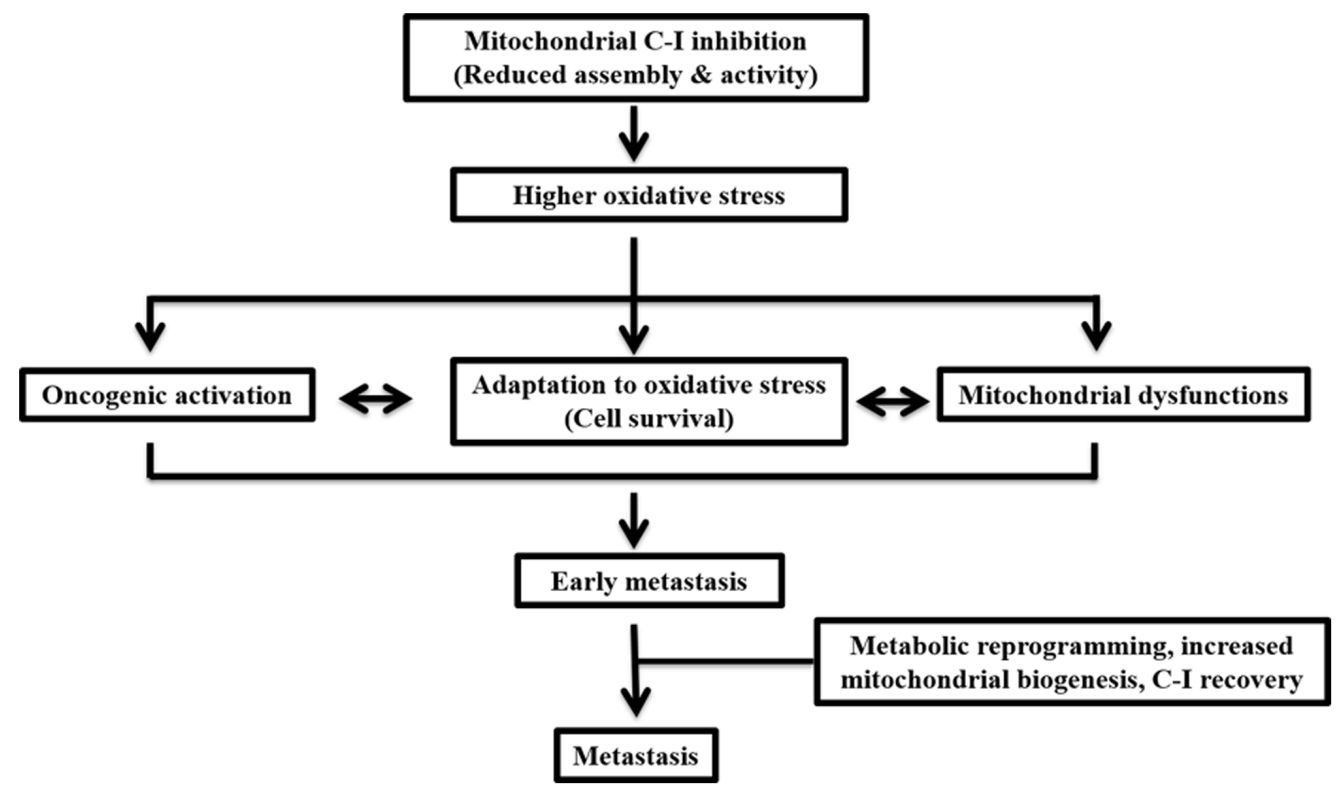

Figure 9. Schematic presentation of the major conclusion of the current study. Functionally compromised C-I leads to increased oxidative stress, mitochondrial dysfunction and oncogenic activation. Together these contribute to the adaptation of cancer cells against oxidative stress in the early metastatic phase. Subsequently, metabolic reprogramming and increased mitochondrial biogenesis with C-I recovery may contribute to enhanced metastatic activity. C-, complex. 
complex process in which cancer cells modify their metabolic requirements for growth and proliferation to achieve metastasis (41). It has been proposed that mitochondria are implicated in the malignant transformation of healthy cells mainly by three major mechanisms: i) By generating ROS or oxidative stress, which may cause oncogenic mutations and activation of oncogenic signaling (42); ii) reprogramming of mitochondrial metabolic pathways, leading to accumulation of onco-metabolites (43); and iii) resistance to mitochondrial permeability transition-driven cell death (44). Among these mechanisms, oxidative stress has been examined extensively, and several studies have reported that oxidative stress serves a major role in malignant transformation of primary tumors and enhances their metastatic potential $(6,7,16)$. However, the precise role of ROS is debatable as the threshold levels of ROS vary between cancer cell types, cancer cell responses and signaling mechanisms to ROS insults.

Mitochondrial RC complexes, mainly C-I and C-III, are involved in generating the majority of free radicals from mitochondria $(27,29)$. Thus, it is important to understand the specific changes in these RC complexes, as well as their contribution in altering the mitochondrial functions and associated signaling pathways. Since CRC rapidly progresses to metastatic phase, the present study used CRC cells with different metastatic potential as in vitro model systems. The current report investigated the effect of mitochondrial stress on respiratory complexes, to understand the functional changes in these complexes and their contribution in metastatic signaling.

The metastatic properties of CRC cells were validated in vitro, and it was demonstrated that HCT-116 cells were more aggressive and metastatic in nature compared with HT-29 cells. Although healthy colon cells would be a more appropriate choice for comparison with low and high metastasis, due to non-availability of these cells and the present focus on comparing low and high metastasis, a known pair of low (HT-29) and high metastatic cells (HCT-116) were selected for the current study. The response of these cells towards mitochondrial RC inhibition and their adaptability of higher oxidative stress were investigated.

Since ROS are generated by leakage of electrons from $\mathrm{RC}$ complexes, the present study examined the effect of $\mathrm{RC}$ inhibition primarily via C-I and C-III, which are major contributors of mitochondrial oxidative stress-induced cell death in mammalian cells $(27,29)$. Low metastatic HT-29 cells were found to be more resistant to C-I inhibition compared with HCT-116 cells, suggesting a higher threshold for C-I mediated oxidative stress in low metastatic conditions. These findings were further corroborated by increased tolerance and improved adaptation to additional oxidative stress by low metastatic cells, as evidenced by their resistance to higher concentrations of $\mathrm{H}_{2} \mathrm{O}_{2}$ and significant recovery after antioxidant treatment compared with other cells. In general, increasing oxidative stress beyond the threshold in cancer cells has been key for current cancer therapeutics to induce targeted cancer cell death (45). However, in multiple types of tumors, including prostate, melanoma and breast cancer, the increased metastatic ability of tumor cells is positively associated with their intracellular ROS levels (46), and exogenous treatment of ROS can enhance certain stages of metastasis (47). The present results suggested a higher tolerance to oxidative stress in low metastatic conditions compared with in high metastatic conditions. Furthermore, inducing apoptosis by enhancing oxidative stress may not be an effective strategy in early stages, as it may significantly enhance cytotoxicity in healthy cells and contribute to detrimental outcomes.

Previous studies have reported that partial impairment of $\mathrm{C}$-I due to heteroplasmic mtDNA mutation in C-I subunit gene increases tumorigenic potential via ROS-mediated oncogenic activation $(10,12)$. An inhibitory effect on tumorigenesis is observed when these C-I defects are severe during conditions of homoplasmic mtDNA mutations in the same C-I subunit gene (10). Moreover, other studies on nuclear encoded C-I subunits or assembly proteins revealed that these C-I associated proteins act as tumor suppressors (48-50). However, there is no consensus on the role of C-I subunits, as several findings observed the upregulation of these proteins in tumor samples $(51,52)$, which may be due to their differential involvement during metastatic process (15). The present study demonstrated that C-I sassembly and activity were inhibited in low metastatic cells compared with high metastatic cells, indicating that inhibited C-I may limit the cellular ability for rapid metastatic transformations. Analysis of mitochondrial functions demonstrated that low metastatic cells with C-I inhibition had increased ROS levels and decreased ATP levels.

The metastatic process involves cell proliferation at distal sites, adaptation to low oxygen environment, metabolic reprogramming and activation of cellular recycling machinery; thus, the contribution of different component of these signaling pathways in metastatic cells was investigated. Mitochondrial alteration, specifically activated via C-I defects, is associated with activation of AKT, which inhibits apoptotic proteins, leading to cell survival in stressed conditions $(10,53)$. The current study further identified that increased phosphorylation of $\mathrm{AKT}$ in low metastatic conditions may provide a survival advantage, specifically to oxidatively-stressed and energy-deprived cells, acting as an adaptive response. This finding was in line with previous reports, which suggested that AKT upregulation is an early event in colon carcinogenesis and is more common in sporadic cases compared with microsatellite instability-high colon cancer cases $(54,55)$. AKT is differentially regulated in CRC, and specifically, the AKT-1 isoform has opposite and inhibitory effect on metastasis compared with other isoforms (56). In the current study, the mRNA expression profiling of AKT-1 and immunoblotting results indicated that low metastatic cells demonstrated increased oncogenic AKT signaling compared with high metastatic cells. Thus, it was hypothesized that while this enhanced AKT signaling may contribute to local cellular proliferation and cellular adaptation of low metastatic cells to high oxidative stress, it may be insufficient for metastatic progression. In addition, this process may involve metabolic alterations and activation of angiogenic pathways for adaptation to microenvironment at distal sites. High metastatic cells had increased mitochondrial biogenesis to restore C-I and mitochondrial functions, and C-I and mitochondrial functions were compromised during early metastasis, as observed in low metastatic cells

Similarly, during metastatic transformation, cells experience low oxygen levels, and therefore, stabilize hypoxia 
inducible transcription factors, such as hypoxia inducible factor 1 subunit $\alpha(H I F 1-\alpha)$, which activates several downstream targets, including the glucose transporter solute carrier family 2 member 1 (SLC2A1) (57), Survivin for anti-apoptosis (58) and angiogenic factors, such as carbonic anhydrase-9 (CA-9) (59) and VEGF (60), which are associated with tumor invasion and metastasis. The cMyc oncogene, an important transcription factor, is a key regulator of mitochondrial biogenesis and targets 100s of mitochondrial genes (61). Oncogenic activation of cMyc is reported to increase biosynthetic and respiratory capacity, and contribute to upregulating glycolytic and mitochondrial metabolism for enhanced metastatic potential (61). Although mitochondrial biogenesis and HIF1- $\alpha$ expression are inversely related in certain cancer types, a positive correlation between these factors has also been revealed during $\mathrm{cMyc}$ activation and confers metabolic advantages to tumor cells, which tend to exist in a hypoxic microenvironment (62). The present study observed a synergistic role of mitochondrial biogenesis, cMyc and HIF1- $\alpha$ in high metastatic cells that may explain the restoration of C-I expression and activity, decreasing ROS levels and partially improving ATP levels, thus indicating their role in enhancing metastatic activity. Furthermore, gene expression analysis identified the upregulation of HIF1- $\alpha$ targeted genes, such as the glucose transporter SLC2A1, the anti-apoptotic protein Survivin and the metastatic markers, VEGF and CA-9, suggesting a metabolic reprogramming mechanism in high metastatic cells that may contribute to their aggressiveness.

The current study demonstrated a direct association of C-I functions in metastatic signaling, as inhibition of C-I in high metastatic cells resulted in a decrease in oncogenic and metastatic signaling, leading to a decline in cellular viability. Therefore, the results highlighted the role of functional C-I in the survival of high metastatic cells. Highly metastatic cells demonstrate aggressive features and can survive under harsh environments, including oxidative stress (63), and the current study observed elevated levels of the antioxidant enzyme SOD1, which is known to scavenge cytoplasmic free radicals (64). This partly explains the lower levels of ROS in high metastatic cells compared with low metastatic cells. In addition, the upregulation of the autophagy-indicator proteins Beclin-1 and ATG5 was found in high metastatic cells. Autophagy has reported to serve an important role in different stages of metastasis (65). Specifically in CRC, autophagy exerts a pro-active effect as revealed by increased expression of Beclin-1 (66) and inhibition of ATG5, which results in an inhibitory effect on tumorigenesis both in vitro and in vivo (67). Therefore, upregulation of these proteins in high metastatic cells indicates a positive contribution of autophagy in metastasis, possibly by enhanced clearance of damaged mitochondria via mitophagy, but this requires further investigation.

There are certain limitations to the present study, including the lack of investigation into the specific components of these signaling pathways associated with C-I functionality and the absence of in vivo experiments. The effect of complex IV (C-IV) inhibition, could not be determined due to potential hazard and regulatory restriction on the use of C-IV inhibitor potassium cyanide. The upregulation of autophagy proteins indicated the role of autophagy in metastasis. However, the role of selective clearance of mitochondria via mitophagy requires further investigation. Therefore, additional studies are required to identify molecular mechanism of C-I targeting molecules and their potential use in developing effective therapies for highly fatal metastatic cancer types.

In conclusion, the present study demonstrated that, during early metastasis, impairments in C-I may contribute to enhanced ROS levels, which may lead to cellular adaptation via activation of cell survival pathways (Fig. 9). In a state of high metastasis, cells may be reprogrammed via a coordinated upregulation of mitochondrial biogenesis and $\mathrm{cMyc}$ to restore $\mathrm{C}-\mathrm{I}$ and the overall mitochondrial functions required for their aggressive features. The current results also suggested that threshold levels of ROS depend on C-I activity and the level of metastasis. Therefore, these should be considered when selecting therapies for cancer, as the threshold and adaptation for oxidative stress are different in early and late phases of metastasis, and can change the outcome of the disease after pro- or anti-oxidant therapies. Moreover, a functional role of C-I was identified, and suggested C-I as a potential therapeutic target for highly metastatic cancer types that are otherwise resistant to chemotherapy.

\section{Acknowledgements}

The authors would like to thank Dr Lia R. Edmunds (University of Pittsburgh) for proofreading the manuscript.

\section{Funding}

Funding was received from Science and Engineering Research Board (grant nos. SB/YS/LS-95/2013 and CRG/2018/001559) and DBT Bio-CARe grant (grant no. BT/P19357/BIC/101/927/2016). NKR was supported by junior research fellowship [grant no. 16-6 (Dec.2017)/2018] from CSIR-UGC.

\section{Availability of data and materials}

The datasets used and/or analyzed during the current study are available from the corresponding author on reasonable request.

\section{Authors' contributions}

NKR, SM and SKS planned and performed the experiments, complied and analyzed the data. MT, ST and LKS were involved in study design, planning of experiments, data analysis and interpretation and writing the manuscript. $\mathrm{RH}$ helped in performing experiments on additional cell lines to validate the findings. VKS was involved in statistical analysis and revising the manuscript critically for important intellectual content. All authors read and approved the final manuscript.

\section{Ethics approval and consent to participate}

Not applicable.

\section{Patient consent for publication}

Not applicable. 


\section{Competing interests}

The authors declare that they have no competing interests.

\section{References}

1. Zorov DB, Juhaszova M and Sollott SJ: Mitochondrial reactive oxygen species (ROS) and ROS-induced ROS release. Physiol Rev 94: 909-950, 2014.

2. Simon HU, Haj-Yehia A and Levi-Schaffer F: Role of reactive oxygen species (ROS) in apoptosis induction. Apoptosis 5 415-418, 2000

3. Wallace DC: Mitochondria as chi. Genetics 179: 727-735, 2008.

4. Vyas S, Zaganjor E and Haigis MC: Mitochondria and cancer. Cell 166: 555-566, 2016.

5. Schieber $M$ and Chandel NS: ROS function in redox signaling and oxidative stress. Curr Biol 24: R453-R462, 2014

6. Le Gal K, Ibrahim MX, Wiel C, Sayin VI, Akula MK, Karlsson C, Dalin MG, Akyürek LM, Lindahl P, Nilsson J and Bergo MO: Antioxidants can increase melanoma metastasis in mice. Sci Transl Med 7: 308re8, 2015.

7. Piskounova E, Agathocleous M, Murphy MM, Hu Z Huddlestun SE,ZhaoZ, Leitch AM,Johnson TM,DeBerardinis RJ and Morrison SJ: Oxidative stress inhibits distant metastasis by human melanoma cells. Nature 527: 186-191, 2015.

8. Ward PS and Thompson CB: Metabolic reprogramming: A cancer hallmark even warburg did not anticipate. Cancer Cell 21: 297-308, 2012.

9. Lu J, Sharma LK and Bai Y: Implications of mitochondrial DNA mutations and mitochondrial dysfunction in tumorigenesis Cell Res 19: 802-815, 2009.

10. Park JS, Sharma LK, Li H, Xiang R, Holstein D, Wu J, Lechleiter J, Naylor SL, Deng JJ, Lu J and Bai Y: A heteroplasmic, not homoplasmic, mitochondrial DNA mutation promotes tumorigenesis via alteration in reactive oxygen species generation and apoptosis. Hum Mol Genet 18: 1578-1589, 2009.

11. Santidrian AF, Matsuno-Yagi A, Ritland M, Seo BB, LeBoeuf SE Gay LJ, Yagi T and Felding-Habermann B: Mitochondrial complex I activity and $\mathrm{NAD}^{+} / \mathrm{NADH}$ balance regulate breast cancer progression. J Clin Invest 123: 1068-1081, 2013.

12. Sharma LK, Fang H, Liu J, Vartak R, Deng J and Bai Y: Mitochondrial respiratory complex I dysfunction promotes tumorigenesis through ROS alteration and AKT activation. Hum Mol Genet 20: 4605-4616, 2011.

13. Sharma LK, Lu J and Bai Y: Mitochondrial respiratory complex I: Structure, function and implication in human diseases. Curr Med Chem 16: 1266-1277, 2009.

14. Urra FA, Munoz F, Lovy A and Cardenas C: The mitochondrial complex(I)ty of cancer. Front Oncol 7: 118, 2017.

15. Leone G, Abla H, Gasparre G, Porcelli AM and Iommarini L: The oncojanus paradigm of respiratory complex I. Genes (Basel) 9: 243, 2018.

16. Gill JG, Piskounova E and Morrison SJ: Cancer, oxidative stress, and metastasis. Cold Spring Harb Symp Quant Biol 81: 163-175, 2016.

17. Bray F, Ferlay J, Soerjomataram I, Siegel RL, Torre LA and Jemal A: Global cancer statistics 2018: GLOBOCAN estimates of incidence and mortality worldwide for 36 cancers in 185 countries. CA Cancer J Clin 68: 394-424, 2018.

18. Edmunds LR, Sharma L, Wang H, Kang A, d'Souza S, Lu J, McLaughlin M, Dolezal JM, Gao X, Weintraub ST, et al: c-Myc and AMPK control cellular energy levels by cooperatively regulating mitochondrial structure and function. PLoS One 10 e0134049, 2015

19. Wittig I, Karas M and Schagger H: High resolution clear native electrophoresis for in-gel functional assays and fluorescence studies of membrane protein complexes. Mol Cell Proteomics 6 : $1215-1225,2007$

20. Fang H, Liu X, Shen L, Li F, Liu Y, Chi H, Miao H, Lu J and Bai Y: Role of mtDNA haplogroups in the prevalence of knee osteoarthritis in a southern Chinese population. Int J Mol Sci 15: 2646-2659, 2014.

21. Schmittgen TD and Livak KJ: Analyzing real-time PCR data by the comparative C(T) method. Nat Protoc 3: 1101-1108, 2008.

22. Li QF, Wang XR, Yang YW and Lin H: Hypoxia upregulates hypoxia inducible factor (HIF)-3alpha expression in lung epithelial cells: Characterization and comparison with HIF-1alpha. Cell Res 16: 548-558, 2006.
23. Onishi Y, Ueha T, Kawamoto T, Hara H, Toda M, Harada R, Minoda M, Kurosaka M and Akisue T: Regulation of mitochondrial proliferation by PGC-1 $\alpha$ induces cellular apoptosis in musculoskeletal malignancies. Sci Rep 4: 3916, 2014.

24. Spandidos A, Wang X, Wang H and Seed B: PrimerBank: A resource of human and mouse PCR primer pairs for gene expression detection and quantification. Nucleic Acids Res 38 D792-D799, 2010

25. Wheaton WW, Weinberg SE, Hamanaka RB, Soberanes S, Sullivan LB, Anso E, Glasauer A, Dufour E, Mutlu GM, Budigner GS and Chandel NS: Metformin inhibits mitochondrial complex I of cancer cells to reduce tumorigenesis. Elife 3: $\mathrm{e} 02242,2014$

26. Salehi MH, Kamalidehghan B, Houshmand M, Meng GY, Sadeghizadeh M, Aryani O and Nafissi S: Gene expression profiling of mitochondrial oxidative phosphorylation (OXPHOS) complex I in Friedreich ataxia (FRDA) patients. PLoS One 9: e94069, 2014

27. Chen Q, Vazquez EJ, Moghaddas S, Hoppel CL and Lesnefsky EJ: Production of reactive oxygen species by mitochondria: Central role of complex III. J Biol Chem 278: 36027-36031, 2003.

28. Cocheme HM and Murphy MP: Complex I is the major site of mitochondrial superoxide production by paraquat. J Biol Chem 283: 1786-1798, 2008.

29. Dröse S and Brandt U: Molecular mechanisms of superoxide production by the mitochondrial respiratory chain. Adv Exp Med Biol 748: 145-169, 2012.

30. Palmer G, Horgan DJ, Tisdale H, Singer TP and Beinert H: Studies on the respiratory chain-linked reduced nicotinamide adenine dinucleotide dehydrogenase. XIV. Location of the sites of inhibition of rotenone, barbiturates, and piericidin by means of electron paramagnetic resonance spectroscopy. J Biol Chem 243: 844-847, 1968

31. Huang LS, Cobessi D, Tung EY and Berry EA: Binding of the respiratory chain inhibitor antimycin to the mitochondrial bc1 complex: A new crystal structure reveals an altered intramolecular hydrogen-bonding pattern. J Mol Biol 351: 573-597, 2005.

32. Penefsky HS: Mechanism of inhibition of mitochondrial adenosine triphosphatase by dicyclohexylcarbodiimide and oligomycin: Relationship to ATP synthesis. Proc Natl Acad Sci USA 82: 1589-1593, 1985.

33. Trainer DL, Kline T, McCabe FL, Faucette LF, Field J, Chaikin M, Anzano M, Rieman D, Hoffstein S, Li DJ, et al: Biological characterization and oncogene expression in human colorectal carcinoma cell lines. Int J Cancer 41: 287-296, 1988.

34. Singh M, Sharma H and Singh N: Hydrogen peroxide induces apoptosis in HeLa cells through mitochondrial pathway. Mitochondrion 7: 367-373, 2007.

35. Viola HM, Arthur PG and Hool LC: Transient exposure to hydrogen peroxide causes an increase in mitochondria-derived superoxide as a result of sustained alteration in L-type $\mathrm{Ca}^{2+}$ channel function in the absence of apoptosis in ventricular myocytes. Circ Res 100: 1036-1044, 2007.

36. Whittemore ER, Loo DT, Watt JA and Cotman CW: A detailed analysis of hydrogen peroxide-induced cell death in primary neuronal culture. Neuroscience 67: 921-932, 1995.

37. Xiang J, Wan C, Guo R and Guo D: Is hydrogen peroxide a suitable apoptosis inducer for all cell types? Biomed Res Int 2016: $7343965,2016$.

38. Clay Montier LL, Deng JJ and Bai Y: Number matters: Control of mammalian mitochondrial DNA copy number. J Genet Genomics 36: 125-131, 2009

39. Virbasius JV and Scarpulla RC: Activation of the human mitochondrial transcription factor A gene by nuclear respiratory factors: A potential regulatory link between nuclear and mitochondrial gene expression in organelle biogenesis. Proc Natl Acad Sci USA 91: 1309-1313, 1994

40. van Zijl F, Krupitza G and Mikulits W: Initial steps of metastasis: Cell invasion and endothelial transmigration. Mutat Res 728 23-34, 2011.

41. Phan LM, Yeung SC and Lee MH: Cancer metabolic reprogramming: Importance, main features, and potentials for precise targeted anti-cancer therapies. Cancer Biol Med 11: 1-19, 2014.

42. Sabharwal SS and Schumacker PT: Mitochondrial ROS in cancer: Initiators, amplifiers or an Achilles' heel? Nat Rev Cancer 14: 709-721, 2014.

43. Sullivan LB, Gui DY and Vander Heiden MG: Altered metabolite levels in cancer: Implications for tumour biology and cancer therapy. Nat Rev Cancer 16: 680-693, 2016. 
44. Izzo V, Bravo-San Pedro JM, Sica V, Kroemer G and Galluzzi L: Mitochondrial permeability transition: New findings and persisting uncertainties. Trends Cell Biol 26: 655-667, 2016.

45. Wang $\mathrm{J}$ and Yi J: Cancer cell killing via ROS: To increase or decrease, that is the question. Cancer Biol Ther 7: 1875-1884, 2008.

46. Lim SD, Sun C, Lambeth JD, Marshall F, Amin M, Chung L, Petros JA and Arnold RS: Increased Nox1 and hydrogen peroxide in prostate cancer. Prostate 62: 200-207, 2005.

47. Jing X, Ueki N, Cheng J, Imanishi H and Hada T: Induction of apoptosis in hepatocellular carcinoma cell lines by emodin. Jpn J Cancer Res 93: 874-882, 2002.

48. He X, Zhou A, Lu H, Chen Y, Huang G, Yue X, Zhao P and Wu Y: Suppression of mitochondrial complex I influences cell metastatic properties. PLoS One 8: e61677, 2013.

49. Kalakonda S, Nallar SC, Jaber S, Keay SK, Rorke E, Munivenkatappa R, Lindner DJ, Fiskum GM and Kalvakolanu DV: Monoallelic loss of tumor suppressor GRIM-19 promotes tumorigenesis in mice. Proc Natl Acad Sci USA 110: E4213-E4222, 2013.

50. Li LD, Sun HF, Liu XX, Gao SP, Jiang HL, Hu X and Jin W: Down-regulation of NDUFB9 promotes breast cancer cell proliferation, metastasis by mediating mitochondrial metabolism. PLoS One 10: e0144441, 2015.

51. Su CY, Chang YC, Yang CJ, Huang MS and Hsiao M: The opposite prognostic effect of NDUFS1 and NDUFS8 in lung cancer reflects the oncojanus role of mitochondrial complex I. Sci Rep 6 : 31357, 2016.

52. Suhane S, Berel D and Ramanujan VK: Biomarker signatures of mitochondrial NDUFS3 in invasive breast carcinoma. Biochem Biophys Res Commun 412: 590-595, 2011.

53. Pelicano H, Xu RH, Du M, Feng L, Sasaki R, Carew JS, Hu Y, Ramdas L, Hu L, Keating MJ, et al: Mitochondrial respiration defects in cancer cells cause activation of Akt survival pathway through a redox-mediated mechanism. J Cell Biol 175: 913-923, 2006.

54. Agarwal E, Brattain MG and Chowdhury S: Cell survival and metastasis regulation by Akt signaling in colorectal cancer. Cell Signal 25: 1711-1719, 2013.

55. Roy HK, Olusola BF, Clemens DL, Karolski WJ, Ratashak A, Lynch HT and Smyrk TC: AKT proto-oncogene overexpression is an early event during sporadic colon carcinogenesis Carcinogenesis 23: 201-205, 2002

56. Ericson K, Gan C, Cheong I, Rago C, Samuels Y, Velculescu VE, Kinzler KW, Huso DL, Vogelstein B and Papadopoulos N: Genetic inactivation of AKT1, AKT2, and PDPK1 in human colorectal cancer cells clarifies their roles in tumor growth regulation. Proc Natl Acad Sci USA 107: 2598-2603, 2010.
57. Chen C, Pore N, Behrooz A, Ismail-Beigi F and Maity A: Regulation of glut1 mRNA by hypoxia-inducible factor-1. Interaction between H-ras and hypoxia. J Biol Chem 276: 9519-9525, 2001

58. Chen P, Zhu J, Liu DY, Li HY, Xu N and Hou M: Over-expression of survivin and VEGF in small-cell lung cancer may predict the poorer prognosis. Med Oncol 31: 775, 2014.

59. Loncaster JA, Harris AL, Davidson SE, Logue JP, Hunter RD, Wycoff CC, Pastorek J, Ratcliffe PJ, Stratford IJ and West CM: Carbonic anhydrase (CA IX) expression, a potential new intrinsic marker of hypoxia: Correlations with tumor oxygen measurements and prognosis in locally advanced carcinoma of the cervix. Cancer Res 61: 6394-6399, 2001.

60. Shweiki D, Itin A, Soffer D and Keshet E: Vascular endothelial growth factor induced by hypoxia may mediate hypoxia-initiated angiogenesis. Nature 359: 843-845, 1992.

61. Li F, Wang Y, Zeller KI, Potter JJ, Wonsey DR, O'Donnell KA, Kim JW, Yustein JT, Lee LA and Dang CV: Myc stimulates nuclearly encoded mitochondrial genes and mitochondrial biogenesis. Mol Cell Biol 25: 6225-6234, 2005.

62. Dang CV, Kim JW, Gao P and Yustein J: The interplay between MYC and HIF in cancer. Nat Rev Cancer 8: 51-56, 2008.

63. Kumari S, Badana AK, Gavara MM, Gugalavath S and Malla R: Reactive oxygen species: A key constituent in cancer survival. Biomark Insights 13: 1177271918755391, 2018.

64. Che M, Wang R, Li X, Wang HY and Zheng XFS: Expanding roles of superoxide dismutases in cell regulation and cancer. Drug Discov Today 21: 143-149, 2016.

65. Mowers EE, Sharifi MN and Macleod KF: Autophagy in cancer metastasis. Oncogene 36: 1619-1630, 2017.

66. Ahn CH, Jeong EG, Lee JW, Kim MS, Kim SH, Kim SS, Yoo NJ and Lee SH: Expression of beclin-1, an autophagy-related protein, in gastric and colorectal cancers. APMIS 115: 1344-1349, 2007.

67. Sakitani K, Hirata Y, Hikiba Y, Hayakawa Y, Ihara S, Suzuki H, Suzuki N, Serizawa T, Kinoshita H, Sakamoto K, et al: Inhibition of autophagy exerts anti-colon cancer effects via apoptosis induced by p53 activation and ER stress. BMC Cancer 15: 795, 2015.

This work is licensed under a Creative Commons Attribution-NonCommercial-NoDerivatives 4.0 International (CC BY-NC-ND 4.0) License. 